\title{
Reflexes of ${ }^{*} r$ in the Alphabetic Dialects
}

\section{Introduction}

This chapter discusses and evaluates the evidence for the regular outcome of ${ }^{*} r$ in the alphabetic Greek dialects other than Ionic-Attic. ${ }^{1}$

The first aim is to determine under which conditions and in which dialects $o$-colored reflexes are regular. There is currently no consensus on this matter. The case for $a$-colored reflexes in dialects like Arcadian and Cypriot has been overstated: Morpurgo Davies (1968), though an influential treatment, suffers from a lack of clarity about Pan-Greek developments that yielded - $\alpha \rho$ - at an early date, such as those involving laryngeals. This issue has been clarified by previous scholars (García Ramón 1985, Haug 2002) and will not be discussed in all its details here.

The second main aim is to determine, for each dialect, the regular place of the anaptyctic vowel. Surprisingly, only few previous discussions have paid attention to this issue: the main focus is usually on determining the vowel color of the regular reflex. There is a broadly-shared presupposition that the apparent hesitation between - $\alpha \rho$ - and - $\rho \alpha$ - in Ionic-Attic was also characteristic of other Greek dialects. In fact, some scholars suppose that in most lexemes the place of the anaptyctic shwa was fixed already in Proto-Greek; this shwa would have merged with /a/ or /o/ later, depending on the dialect and in some cases on further phonetic conditioning factors. However, in the previous chapter we encountered examples where the dialects have a diverging vowel slot in the

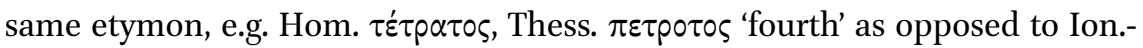

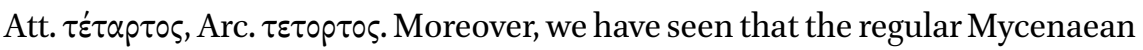
reflex of ${ }^{*} r$ was either -or- or preserved $-r$-, and that there is no need to assume

1 The inscriptional evidence for Ionic-Attic hardly adds anything to the picture obtained from literary sources, and will therefore not be treated separately in this chapter. In Western Ionic, the development of the syllabic liquids was identical to that in the rest of Ionic-Attic (cf. del Barrio 1991). The Euboean colonies in Italy yield the form arappis 'assembly' (Naples), which probably reflects a zero grade root, whereas the literary Ionic-Attic form ó $\gamma \varepsilon p \sigma \varsigma s$ 'mustering of an army' (Hdt.) was rederived from the verb with an $e$-grade root. See the discussion of Arc. $\pi \alpha v \alpha \gamma o p(\sigma)$ เs in section 3.4.3. As for Attic, Threatte (1980) has no separate treatment of the syllabic liquids. An exceptional instance where Attic inscriptions add to the literary evidence is $\varphi \alpha \rho \chi \sigma \alpha \mathrm{l}$ (inscr.) beside $\varphi \rho \alpha \dot{\xi} \alpha$ l 'to fence in, fortify' (mss. of literary authors); it will be discussed in section 9.2.3. 
a separate outcome ${ }^{*} r>-r o$ - for that dialect. The evidence for the vowel slot in the other dialect groups (West Greek dialects, Aeolic, Arcado-Cyprian) must be reconsidered in this light.

The West Greek reflex of ${ }^{*} r$ is normally assumed to be identical to that of Ionic-Attic: - $\rho \alpha$ - is regular, $-\alpha \rho$ - arose by analogy with related forms. On Crete, however, we find a number of forms with - $\alpha \rho$ - for which an analogical explanation is difficult to find. They are the following (for places of attestation, see Bile 1988): ${ }^{2}$

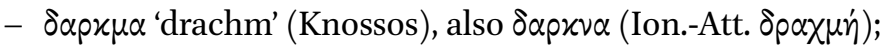

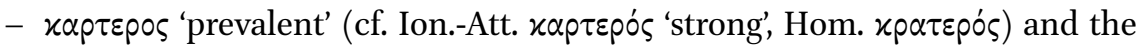
following related words:

- xартољ 'force' (cf. Ion.-Att. xpátos);

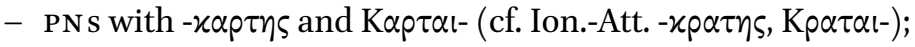

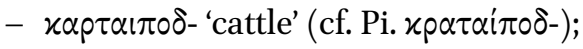

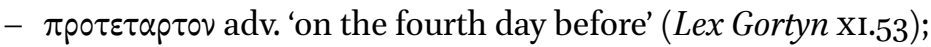

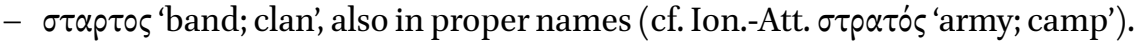

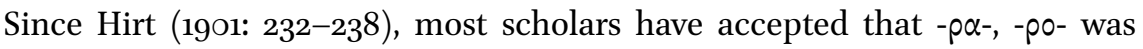
metathesized to - $\alpha p-$, -op- in Cretan. ${ }^{3}$ At first sight, this claim seems reason-

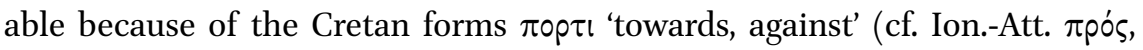

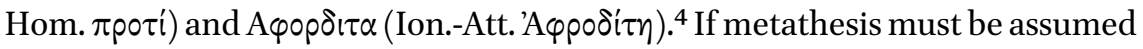
for these forms anyway, Hirt's reasoning goes, it follows that $-\alpha p-<{ }^{*} r$ may have developed through - $\rho \alpha$-. The argument presupposes, however, that the $o$ -

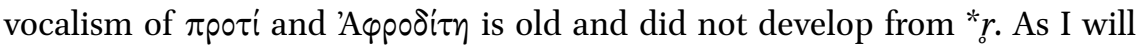
show below, this is not evident at all.

2 Cret. xapтos 'yield, revenue' could be the regular reflex of its pre-form, PGr. *krpó-, but since this word shows $-\alpha p$ - in all dialects where it is attested, its evidential value is limited.

3 In the words of Bechtel (1921-1924, II: 710-711), "In einigen Wörtern und Wortfamilien werden die Lautgruppen $\rho \alpha, \rho \circ \mathrm{zu} \alpha \rho$, o $\rho$ umgestellt. Wie weit dieser Vorgang rein lautlicher Natur sei, wie weit analogische Wirkungen ihn begünstigt haben, kann nicht immer entschieden werden" Cf. also Thumb-Kieckers (1932: 16o), who think that the same phenomenon is found in Argolic, Elis, Pamphylian, and Arcado-Cypriot.

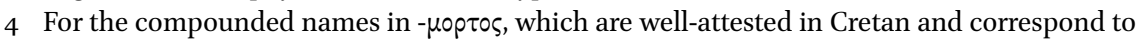
- Bpotos in most other dialects, see section 3.1.2 (with further discussion). Another piece of evidence cited by Hirt is Pamphylian $\pi \varepsilon p \tau$, which allegedly reflects *preti and is related to $\pi \rho \tau^{\prime}, \pi \rho o ́ s$. However, the dialectal affiliations of Pamphylian are unclear, and the same holds for the regular reflex of ${ }^{*} r$ in this dialect (see section 3.5). 
The major problem with the assumption of liquid metathesis in Cretan is the existence of forms with $-\rho \alpha$ - and -po-, such as the following:

- pres. inf. $\alpha \pi \circ \tau \rho \alpha \chi \varepsilon \nu$ 'to run away' (Olous, 3rd c., cf. Class. $\tau \rho \varepsilon ́ \chi \omega$ 'to run');

- pres. opt. $\tau p \alpha \pi$ ol (Eleutherna, 6th c.), inf. $\tau p \alpha \pi \varepsilon \nu$ (Lex Gortyn III.49), impv.

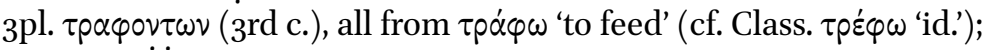

- pres. $\gamma \rho \alpha \varphi \omega$ 'to write' (= Class. $\gamma \rho \alpha \dot{\varphi} \omega$ 'id.);

- xpovos 'time' (Class. xpóvos 'id.');

- $\tau \varepsilon \tau \rho \alpha-$ 'four' in compounds such as $\tau \varepsilon \tau p \alpha \pi \circ \delta$ - 'cattle' (IC IV 41, III 8-9);

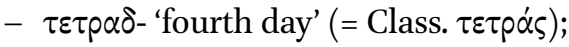

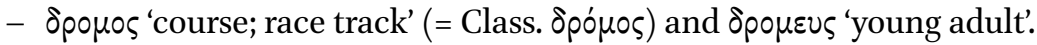

Hirt (1901: 235) discusses some of these examples. He notes that $\tau \rho \alpha \varphi \omega$ may have been influenced by the full grade $\tau p \varepsilon \varphi$-, and that $\gamma \rho \alpha \varphi \omega$, as a technical term, does not carry much weight. Furthermore, he does away with xpovos and

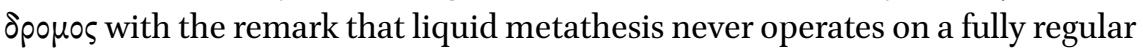
basis, and makes the ad hoc suggestion that they were borrowed from another dialect. This is clearly unsatisfactory. Bile (1988: 125) proposed that - $p \alpha-$ and -powere metathesized in open syllables, but preserved as such in closed syllables. This idea is contradicted by the forms just listed, as well as by $\delta \alpha p \varkappa \mu \alpha / \delta \alpha p \varkappa \nu \alpha$.

Thus, there is no satisfactory explanation of the fluctuations. ${ }^{5}$ It is true that the present stems $\tau \rho \alpha \chi \omega$ and $\tau \rho \alpha \varphi \omega$ can be explained as secondary (see below), and that $\gamma \rho \alpha \varphi \omega$ is a problematic form on any account. ${ }^{6}$ However, the forms

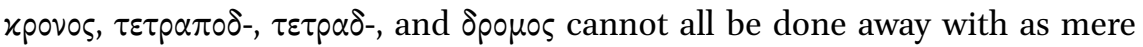
"exceptions" (Bile 1988: 125); they strongly militate against the idea of liquid metathesis. Moreover, if some form of liquid metathesis was operative, one would expect to also find examples of $\rho \varepsilon, \rho l, \rho v$ appearing as $\varepsilon \rho, ~ i p$, up in Cretan. There is no apparent reason why the metathesis would have been restricted to back vowels.

In view of these problems, let us now investigate whether - $\alpha \rho$ - and -op- in Cretan can be viewed as the regular outcomes of ${ }^{*} r$.

5 O'Neil (1971: 43-44) posits a liquid metathesis in Central Cretan only before dental or velar stops, but not before labial or (original) labiovelar stops. This is phonetically unmotivated and also contradicted by $\alpha \pi \circ \tau \rho \alpha \chi \varepsilon \nu$ 'to run away'.

6 The Pan-Greek $a$-vocalism of $\gamma p \dot{\alpha} \varphi \omega$ speaks against a reconstruction PIE * $g r b^{h}-e / o$-. Moreover,

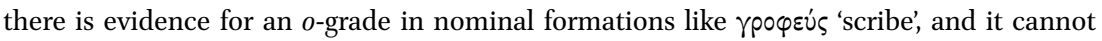
be excluded that $\gamma p \alpha \dot{\varphi} \varphi \omega$ obtained its vowel slot from a (no longer existing) verbal form with *grep ${ }^{h_{-}}$or * grop ${ }^{h}$. See section 9.2.2. 


\subsubsection{Cretan-ap- < "r: Evidence and Counterevidence}

Positing a regular Cretan development ${ }^{*} r>-\alpha \rho$ - immediately explains the

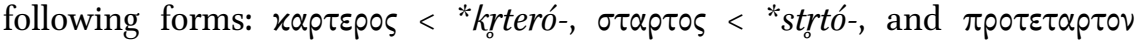

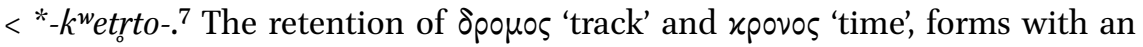
original $o$-vowel for which an analogical explanation seems out of reach, also finds a natural explanation. It remains to account for the Cretan forms with $-\rho \alpha-$.

The reflex seen in $\tau \varepsilon \tau \rho \alpha-\pi \circ \delta \alpha$ 'cattle' and other compounds seems to contradict that of the ordinal $\tau \varepsilon \dot{\tau} \tau \rho \tau \tau$ ऽ. However, just as in Ionic-Attic, the linking vowel of $\tau \varepsilon \tau \rho \alpha$ - may have been taken over from the higher numerals $\dot{\varepsilon} \pi \tau \alpha$-,

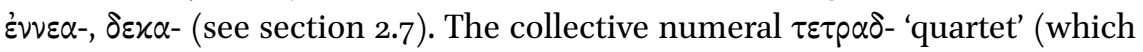
also exists in Ionic-Attic) has a suffix - $\alpha \dot{\delta}$ - that originated in $\delta \varepsilon x \alpha ́ \delta$ - 'group of ten' and derives from a pre-form with syllabic nasal, PIE * dekm-t-. ${ }^{*}$

The remaining counterevidence concerns the so-called "Doric presents" of the type $\tau \rho \alpha \dot{\chi} \chi \omega$, corresponding to class. $\tau \rho \varepsilon \chi \chi \omega$. There are four such verbs in Cretan (see Bile 1988: 124). A zero grade thematic present stem is directly attested in forms of $\tau \rho \alpha \varphi \omega$ and $\tau \rho \alpha \chi \omega$ (see above). In addition, the formation

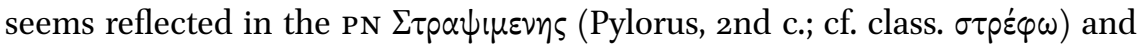
the future $[\varepsilon] \pi i \tau \rho \alpha \psi i \omega$ (Lyttos; cf. Class. $\tau \rho \varepsilon \dot{\psi} \psi \omega$ 'will turn'). ${ }^{9}$ The corresponding Ionic-Attic verbs have an $e$-grade present stem and sigmatic aorist, as opposed to $a$-vocalism in the $\eta$-aorist. A possible scenario would be reconstruct a zero grade root for the thematic root present, i.e. pres. ${ }^{*} d^{h} r g^{h}{ }_{-e} / o^{-}$, beside an $e$-grade root in the aor. ${ }^{*} d^{h} r e g^{h}-s$. If so, Cretan and other West Greek dialects then generalized the $a$-colored reflex throughout the verbal paradigm, while Ionic-Attic extended the $e$-grade root to the present stem. ${ }^{10}$

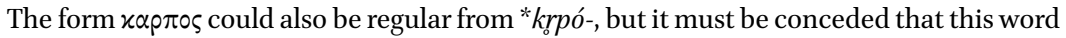
has the same form in all dialects where it is attested. As for $\delta \alpha p \chi \mu \alpha, \delta \alpha p X \nu \alpha$ (if from PGr. $\left.{ }^{*} d r k^{h} m n \bar{a}\right)$, there are various problems in the reconstruction of this word; cf. below on the dialect of Elis.

In Van Beek 2017b, I have argued that the $\delta$ in - $\alpha \delta$ - can be due to voicing of an occlusive after an accented Proto-Greek syllabic nasal. Cf. also Olsen (1989).

9 Comparable epigraphic forms from other West Greek dialect areas are aor. $\alpha \pi 0 \sigma \tau p \alpha \psi \alpha$ l (Delphi, CID 2:34, col. II, 31; 4th c. BCE) and $\varepsilon \xi \sigma \tau p \alpha \varphi \varepsilon \tau \alpha$ ( $S E G$ 30:38o, no. 6, l. 1, Tiryns, ca. 6оO-55 вСЕ?). There is also evidence from literary sources: in Aristophanes (Ach. 788 ), $\tau \rho \alpha \dot{\varphi} \omega \omega$ for $\tau \rho \varepsilon \dot{\varphi} \varphi \omega$ is reputed to be Megarean, and the form is also well-attested in Pindar and perhaps in Theocritus (हैं $\rho \alpha \varphi \varepsilon$ Theoc. 3.16, but with v.l.). Moreover, Pindar uses both $\tau \rho \alpha \dot{\alpha} \chi \omega$

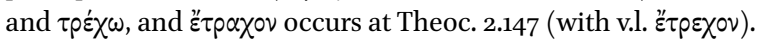

10 See Letoublon \& Lamberterie (1980: 324-325) for further discussion, also on the aspectual status in PIE of formations like * $d^{h} r g^{h}-e / o$-. Willi (2018: $\left.351-355\right)$ now argues against the antiquity of zero-grade thematic root presents in Greek, and in Indo-European more generally. 
In sum, the Cretan evidence for $-\rho \alpha-<{ }^{*} r$ is easily reconciled with a regular development to - $\alpha \rho$ - in that dialect. It is unnecessary to assume that - $\rho \alpha-$ underwent liquid metathesis on an irregular basis. In order to further strengthen this conclusion, let us now consider the three forms with -op- for which liquid metathesis has been assumed.

\subsubsection{Cretan-op- $<$ "rofter a Labial Consonant}

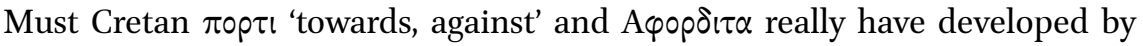

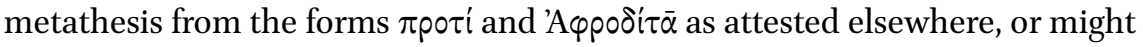

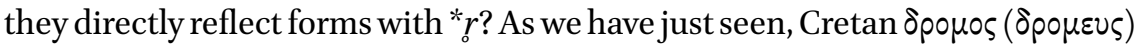
and $x$ povos never contained ${ }^{*} r$, and therefore speak against the assumption of metathesis. Therefore, even if only a plausible case can be made that $\pi \circ \tau^{\prime} \iota$ and A $\varphi$ op $\delta \tau \alpha$ may have a pre-form with ${ }^{*} r$, it is attractive to think that ${ }^{*} r$ became Cretan -op-after labial consonants, but - $\alpha p$ - in all other positions.

The evidence for the alleged pre-form PGr. "proti consists of Ion.-Att. and

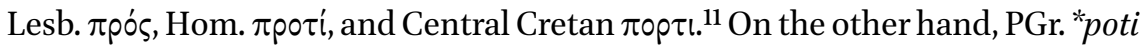
is reflected in Thessalian and Boeotian, perhaps in Arc. $\pi \circ 5$ and Myc. po-si, ${ }^{12}$ as well as all in West Greek dialects other than Central Cretan. Wyatt suggested that Ion.-Att. $\pi$ pós might reflect the prevocalic outcome of "poti contaminated with the -r- of $\pi p$ ó. In Wyatt's view Homeric $\pi$ poti arose in the same way; he also shows that $\pi \circ \rho \tau \iota$ only occurs in Central Cretan, whereas the rest of Crete (like West Greek generally) has $\pi \circ \tau \iota$. He accounts for Cretan $\pi \circ \tau^{\prime} \iota$ by assuming that it represents a contamination of $\pi \circ \tau$ เ with $\pi \varepsilon p i$ (Wyatt 1978: 121 n. 78), and concludes that Proto-Greek had only *poti.

At first sight, Wyatt's scenario offers an attractive reduction of the West Greek situation. However, it is unlikely that Proto-Greek had only *poti because in Homer $\pi p o \tau i$ cannot be secondary beside $\pi \circ \tau i$. A fuller treatment of the Homeric evidence (including muta cum liquida scansions in $\pi$ pós and related forms) will be given in section 7.2.5. Anticipating the conclusions to be reached there, the Homeric evidence favors a reconstruction "prti, and the precursors of $\pi \rho \delta \sigma \omega$ 'forward' and $\pi \rho \delta \sigma \omega \pi \circ v$ 'face' also continue a form starting with "prti-. This means that Proto-Greek had both "poti and " ${ }^{*} r t i,{ }^{13}$ and that Central Cretan $\pi \circ \rho \tau \iota$ can be a retained archaism. The reconstruction "prti also accounts for the

\footnotetext{
11 The existence of $\pi$ po $\tau$ in Argolic is doubtful (cf. Wyatt 1978: 89 n. 1).

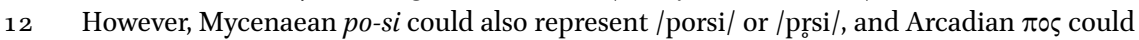
be the regular reflex of * $\pi$ op before a consonant. To my knowledge, this has not been noted before.

13 And possibly also orthotonic "préti, but that is irrelevant here.
} 
scansion of $\pi$ pós and related forms in Homer, while the form $\pi$ pós in Ionic and Attic prose may be ascribed to the influence of another local adverb, either $\pi \rho o ́$ or "poti, on the vocalization of *prti. Furthermore, a zero grade *prti could also account for a related adverbial element in Hittite, parza '-wards.'14

The assumption that Aphrodite's name contained ${ }^{*} r$ may come as a surprise, as it has no established etymology. However, positing a pre-form with ${ }^{*} r$ would be the only reasonable way of accounting for the structural muta cum liquida

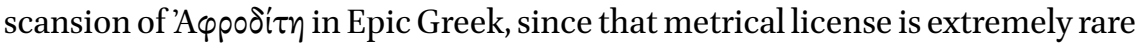
in word-internal position, especially when plosive plus liquid does not follow a synchronic morpheme boundary. ${ }^{15}$

A third potential instance of a Cretan development $-o p-<{ }^{*} r$ after labials

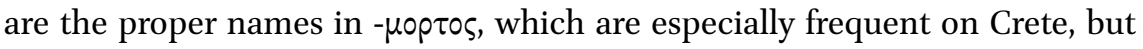
also appear in Lesbian and two West Greek dialects (Theran, Aetolian). Nothing crucially depends on including or excluding this example, but the evidence is suggestive. The simplex is attested only in post-classical sources:

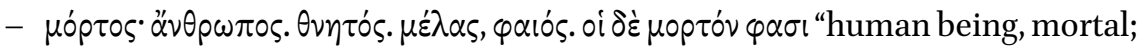

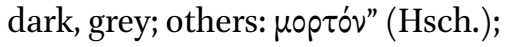

- Call. fr. 467, taken from Ammonius' (5th c. CE) commentary to Aristotle's De

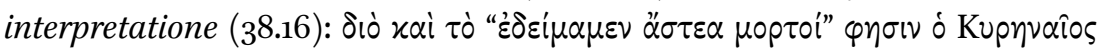
"therefore the Cyrenaean poet says: we mortals have built cities". 16

The evidence as regards the accentuation is conflicting, and it is possible that the gloss in Hesychius refers to more than one attestation. Still, the Callimachus fragment confirms the existence of a word meaning 'mortal, man'. Is

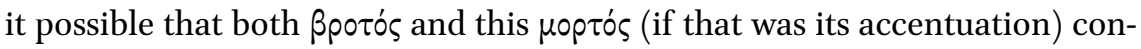

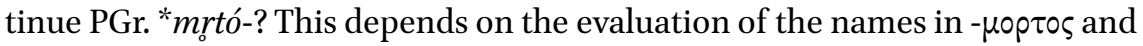
Mopto-, the evidence for which was collected and discussed by Masson (1963: 219):

14 Kloekhorst (EDHIL, q.v.) already reconstructs the Hittite form as PIE *prti, directly comparing Cretan $\pi \circ \rho \tau \iota$ but without accounting for Ionic-Attic $\pi \rho \circ \varsigma$; the analysis proposed here and in chapter 7 may justify this idea.

15 In section 7.2.8, I argue that Aphrodite must be an inherited Greek epithet of the planet Venus (the evening and morning star), and tentatively propose to reconstruct PGr. (or common Greek) * $a p^{h_{r}}$-ditta 'who appears forthwith' (at sunset). The reconstructed compound consists of the precursor of the adverb $\alpha \dot{\alpha} \varphi \alpha \rho$ 'forthwith' and a derivative in -to- of

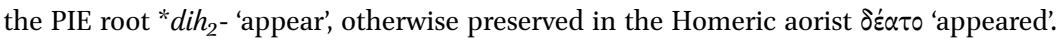

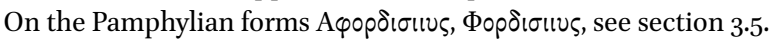

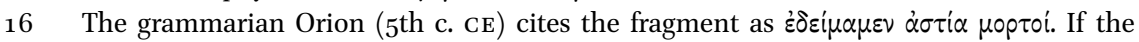
lectio difficilior $\dot{\alpha} \sigma \tau i \alpha$ is the genuine Callimachean form, it would show the common dialectal change $\varepsilon>\iota$ before a vowel and a different accent (secondary, or directly from * $\dot{\alpha} \sigma \tau \varepsilon \dot{\varepsilon} \alpha$ ). 


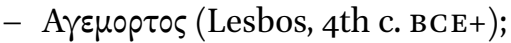

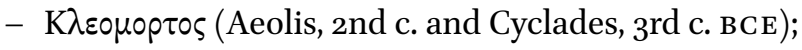

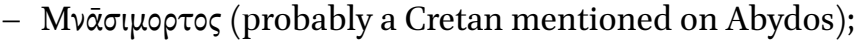

- Xapıroptos (Lato, IC I, 16, 34); name of an Aetolian (3rd c. BCE);

- Moprovāoos (Thera, early 5 th c. BCE).

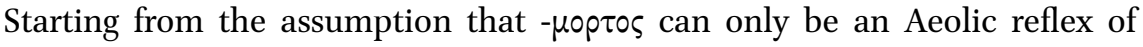
*-mrtó-, Masson reconstructs a pre-form * mórto- beside * $m_{r}$ tó- for Proto-Greek in order to account for the West Greek names. ${ }^{17}$ This would imply that Greek preserved more than one inherited word for 'mortal' from this root. Now, the PIE words for 'mortal' and 'dead' are notoriously hard to reconstruct, ${ }^{18}$ but Mas-

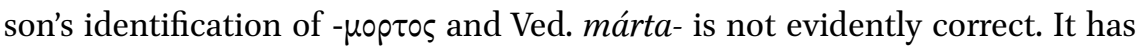
been submitted that Ved. márta- derives not from * mórto-, but from *mérto-, 19 but in any case, there is no unambiguous evidence pointing to PGr. * mórto- (or *mortó-) rather than *mrtó- among the forms just discussed. Masson claims

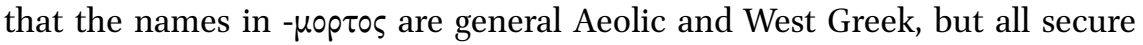
examples of these names are attested in Lesbian, Theran, and Cretan. ${ }^{20}$

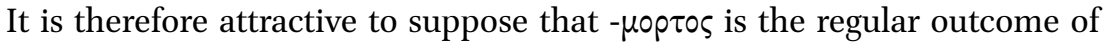
*mrtó- in Cretan and Theran. One might then think that the simplex roptós in Callimachus stems from the dialect of his native town Cyrene, a colony of

17 Masson concludes (1963: 221): “... on ne saurait plus affirmer comme jadis que $\mu$ optós est une forme exclusivement éolienne, soit chez Callimaque, soit dans l'onomastique. En

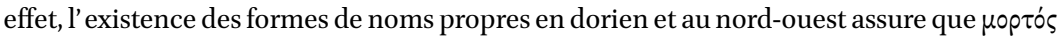

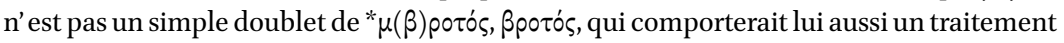
éolien à partir d'un modèle i.-e. *mrtó-, mais avec op au lieu de po. La forme correspond plutôt à un i.-e. "mórto-, avec vocalisme $o$ de la racine *mer-." Masson's judgment is fol-

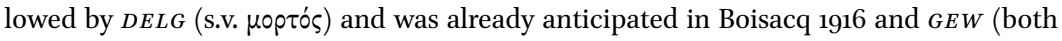
s.v. ßpotós).

18 Indo-Iranian has three forms for 'mortal': (1) Ved. márta- and OAv. (hapax) maša- < PIIr. * márta-, (2) OAv. marata- < PIIr. * martá-, and (3) Ved. mártya-, Av. maśiia-, OP martiya-< PIIr. "mártia- (cf. EWAia s.vv. MAR and márta-). Furthermore, Ved. mrtá- and Av. marətamean 'dead', not 'mortal'. However, since Indo-Iranian preserves the verbal root mar- 'to die', it cannot be excluded that at least some of these formations were later derivations.

19 Katz (1983) argues that Finno-Ugric borrowings from Indo-Iranian point to a pre-form (early) PIIr. *mérto- (where PIIr. *o notes the outcome of PIE *o in closed syllables), to be equated with (later) PIIr. *márta-. This would imply that PIIr. *márta- < PIE *mértocannot be directly compared with the putative Proto-Greek *mórto- assumed by Masson. See further the discussion in Mayrhofer, EWAia s.v. márta-.

20 The Aetolian attestation cited by Masson (1963: 220) is found in an inscription from Egypt, and refers to an officer serving under Ptolemy Philopator (reigned 221-205 BCE). The same person is mentioned by Strabo and Polybius. Even if this relatively late piece of evidence is taken into account, one wonders whether enough is known about reflexes of the syllabic liquids in Aetolian to accept Masson's conclusion that PGr. had a separate form *mórto-. 


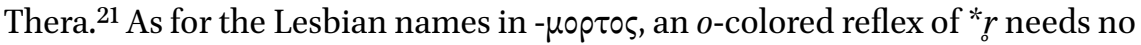
further explanation, but the vowel slot is awkward (because * ${ }^{*} r>$ Aeolic -po-, see section 3.3). One would then have to assume influence of the verbal root *mer- on the vocalization to - op tos for a pre-stage of Lesbian. ${ }^{22}$ In this con-

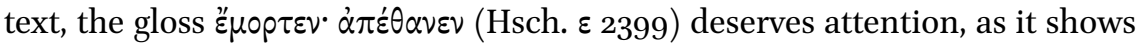
that a reflex of the verbal root * mer- was indeed preserved in some (probably poetic) form of Greek. ${ }^{23}$

In sum, since reconstructing an additional form *mórto- 'mortal' (beside

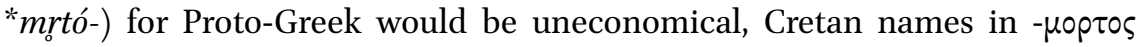
could be an additional argument for a conditioned reflex -op- $<{ }^{*} r$ in Cretan. ${ }^{24}$ The conditioning factor "after labials" for the reflex -op- would make good sense from a phonetic point of view. ${ }^{25}$

\subsection{Other West Greek Dialects}

In this section, we will turn our attention to Laconian and its colonies (especially Theran and Cyrenaean, section 3.2.1), then consider the evidence from Literary Doric (section 3.2.2), and finally make some remarks on the dialects of Elis (section 3.2.3) and the Argolid (section 3.2.4). I have found no noteworthy details for the dialects of Megara (and colonies), for Cos, Rhodes, Karpathos and the other Doric-speaking islands in the Dodecanese, nor for Messenia. For other regions (Achaea, North West Greek), the details are not very interesting

21 It is, of course, impossible to establish the dialectal provenance of $\mu$ optós in Callimachus with certainty. It is also difficult to draw a conclusion from the gloss $\mu \circ \rho \tau o \beta \dot{\alpha} \tau \nu v^{*} \alpha \nu \theta \omega \omega \pi 0-$ $\beta \alpha \dot{\tau} \tau \nu$ vav̂v (Hsch.), in view of the absence of a dialect identification.

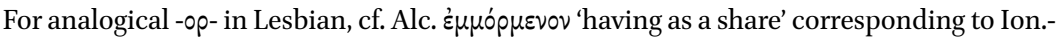
Att. $\varepsilon i \mu \alpha \rho \tau \alpha$.

23 According to Klingenschmitt (apud LIV ${ }^{2}$ s.v. *mer-), है $\mu \circ \rho \tau \varepsilon v$ reflects an older middle in *-to that was reinterpreted as an active form.

24 For the outcome of $* l$ in Cretan, see section 10.6. The conditioning of the distribution

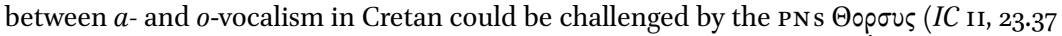

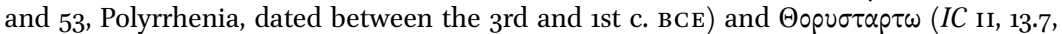
Elyros, 2nd с. BCE). But in Masson's view (1972: 292, accepted by Leukart 1994: 191), these

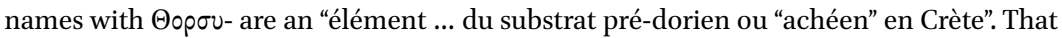
would presuppose, however, that Mycenaean (or its continuation in the sub-Mycenaean period) had an $o$-colored reflex also in a non-labial environment, which is possible (cf. the Arcadian reflex in $\tau \varepsilon \tau o \rho \tau \alpha u)$. On the possibility that Myc. PN $t o-s i-t a$ reflects $/ \mathrm{T}^{\mathrm{h}}{ }_{\mathrm{r}} \mathrm{sitās} / \mathrm{vel}$ sim. $<{ }^{*} d^{h} r s i$-, see section 2.3.1.

25 A similar conditioned reflex has been proposed for Mycenaean and Arcado-Cyprian (e.g. Morpurgo Davies 1968, see section 3.4 below). 
either, as appears from the respective dialectal grammars. ${ }^{26} \mathrm{I}$ will not present a complete overview for all West Greek dialects, but merely try to illustrate the precarious nature of the evidence.

\subsubsection{Laconian and Colonies}

The dialect of Sparta itself is not very well documented in the (pre-)classical period, but its colonies have produced more inscriptions. In Magna Graecia, Heraclea and Tarentum have yielded important epigraphic material; in the Eastern Mediterranean, Thera was probably colonized by Laconians, and Theran settlers then founded Cyrene in Libya.

The evidence for Theran consists mainly of personal names. As far as names are trustworthy evidence, they may provide evidence for the vocalization to - $\alpha \rho$ - (and perhaps also -op- after a labial consonant) that we just established for Cretan: ${ }^{27}$

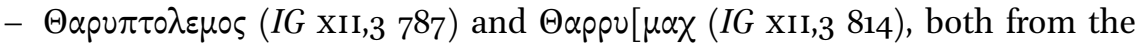
archaic period. $^{28}$

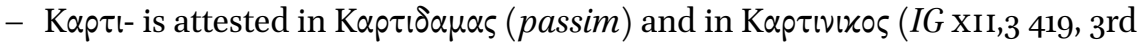
c.), see Bechtel (1917: 256). ${ }^{29}$

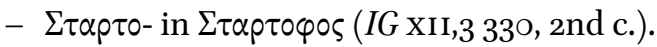

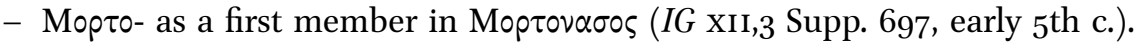
Masson (1963: 220) takes this as the outcome of PGr. *morto-, but in view of reasons given above, it seems more likely that PGr. had only * mrto-.

$\Theta$ @ppu- may be the regular outcome of * $t^{h_{0}} r u$ - or it may have an analogical

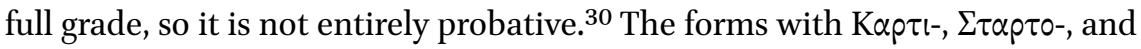
Mopto-, however, are absent from most other Greek dialects. The fact that attestations of these forms are concentrated in Cretan and Theran could suggest a common development of these dialects, but it could also be due to language contact or migrations of the bearers of these names.

The inscriptions from Cyrene, a colony founded by Theran settlers, have been edited by Dobias-Lalou (2000). She discusses the outcome of the syllabic

26 For North-West Greek, see Méndez Dosuna (1985); for the colonies in Magna Graecia, see the various dialect grammars by Arena and Dubois.

27 That - $\alpha p$ - was regular in Theran was already suggested by Bechtel (1921-1924, II: 534 and $556)$.

28 These forms show that Theran underwent the development - $\rho \sigma->-\rho \rho-$. The - $\rho \sigma-$ found in $\Theta \alpha \rho \sigma x p \alpha \tau \eta \varsigma$ on another Theran inscription is probably a Koine form. Generally speaking,

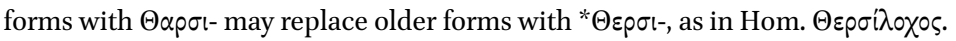

29 As a second member, - $\alpha \alpha \rho \tau$ - is perhaps found in $\Lambda \alpha x[\alpha] \rho \tau \omega \varsigma$ (IG XII,3 1324).

30 See chapter 4 for further details. 
liquids on pages 34-35. Not too much can be deduced from the evidence in appellatives:

- The noun xap Lalou 2000: 195) has the same form in all other dialects; therefore a Koine form or an early borrowing cannot be excluded.

- In view of its special meaning 'chaff' in Cyrenaean, $x \alpha \rho \varphi \circ \varsigma$ could well be a genuine dialectal form (Dobias-Lalou 2000: 195-196). For the reconstruction of ${ }^{*} r$ in the root $x \alpha \rho \varphi-$, see section 9.6.6.

- The form Ypoфeus 'secretary' (SEG 9.13, 16) is otherwise peculiar to the Peloponnese and Crete, but it probably does not reflect a pre-form with * $r$ (see section 9.2.2). The verbal root is $\gamma p \alpha \varphi$ - in Cyrenaean, like in all other Greek dialects.

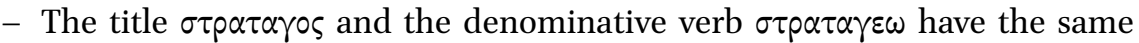
form as elsewhere in West Greek, with the exception of Theran and Cretan. Many of the personal names attested in Cyrenaean may show the influence of Koine or Epic Greek. ${ }^{31}$ This does not apply, however, to the first compound

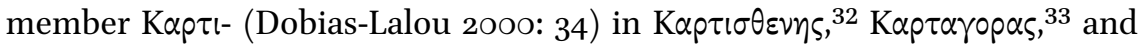

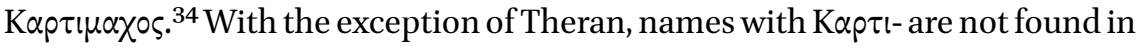
other Greek dialects, not even in Cretan. ${ }^{35}$ They could therefore contain information about the regular Theran and Cyrenaean development of ${ }^{*} r$, and they outweigh $\sigma \tau \rho \alpha \tau \alpha \gamma o \varsigma$, because that form could easily be due to Koine influence. Since Cyrene was colonized from Thera, the vocalization ${ }^{*} r>-\alpha p$ - would have taken place before the settlement of Cyrene. Cyrenaean provides no further counterevidence to this assumption. It is true that evidence gained from personal names must be used with caution, but it is not unlikely that the names

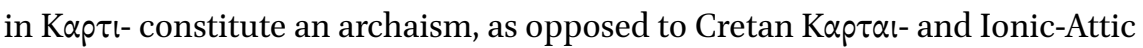

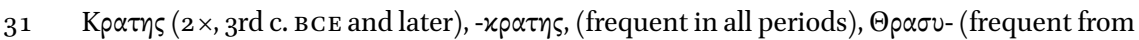
the middle of the 4th c. BCE, Dobias-Lalou p. 35), as a simplex $\Theta \rho \alpha \sigma \omega \nu$ and $\Theta \alpha \rho \sigma \omega \nu$ (both 3 rd c. BCE and later), $\Sigma \tau \rho \alpha \tau 0-(S E G$ 20.735, Dobias-Lalou p. 14) and - $\sigma \tau \rho \alpha \tau \circ \varsigma$, A $\rho \pi \alpha \lambda \varepsilon \dot{\varepsilon} \alpha$ (4th3 rd c., $C I G 5155$ and 3 rd c., $S E G$ 9.92).

32 Frequent from the 4th c. BCE-2nd C. CE. Bechtel (1917: 256) could only ascribe it to the Imperial period.

33 In SEG 9.45, 48 (5th c. BCE) and SECir. 244 (4th c. BCE).

34 Attested in two lists of temple servants, around the beginning of the CE. The sequence

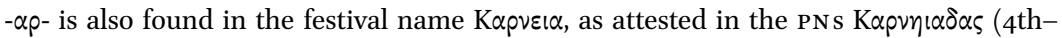

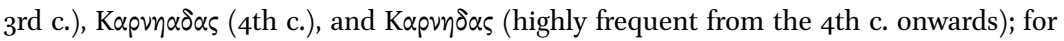
attestations see Dobias-Lalou (2000: 49). The festival belongs to the Laconian heritage of Cyrenaean, but it is unclear whether $-\alpha p$ - reflects a syllabic liquid in this word.

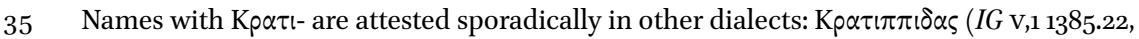
Thuria, 2nd c. BCE), Kp $\alpha \tau$ - $\delta \eta \mu \circ \varsigma$ (Erythrae, No. 57, 5th-4th c. and No. 6o, early 3 rd c. BCE, cited from McCabe, Erythrai inscriptions, text and list). 


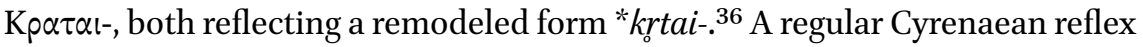
- $\alpha \rho$ - is possibly confirmed by the form $x \alpha \rho \varphi \circ \varsigma^{\text {'chaff'. }}$

\subsubsection{Literary Doric}

How to evaluate the outcome - $\alpha p$ - (and perhaps -op-) in Cretan and Theran with regard to the vocalization in other West Greek dialects? The main question is whether there is any evidence at all for the outcome $-\rho \alpha$ - in these dialects. Unfortunately, it is difficult to reconstruct even scraps of the situation in most of the West Greek dialects.

For Laconian, the closest relative of Theran, the epigraphic material is sparse, but the literary evidence may perhaps offer some clues about the dialectal reflex. In Alcman (worked in Sparta, late 7th c.), Epicharmus (worked in Syracuse, a colony of Corinth, early 5 th c.), Sophron (Syracuse, end half $5^{\text {th }}$ c.) and some other literary sources, we find the comparative $x \dot{\alpha} p \rho \omega \nu$ 'better', from an earlier ${ }^{*} k r t i o ̄ n .37$ In Cretan, this comparative has been restored as xaptov-. ${ }^{38}$ Apparently, the zero grade of the positive xaptepos has been introduced into the comparative both in Cretan and in the dialect(s) underlying xápp $\omega v$. But from which specific dialect(s) was $x \alpha$ áp $\omega \nu$ taken?

It is likely that $x \dot{\alpha} p \rho \omega \nu$ was not the regular outcome of * $k r t i o ̄ n$ in all Doric vernaculars. The Syracusan mimographer Sophron used a middle perfect ptc.

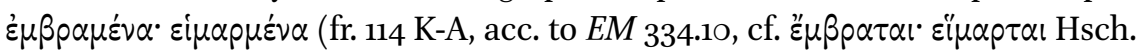
$\varepsilon 2313$ ) as well as an aorist 2sg. है $\pi \rho \alpha \delta \varepsilon \varsigma$ 'you farted' (fr. $136 \mathrm{~K}-\mathrm{A}$, contrast है $\pi \alpha \rho-$ $\delta o v$ in Attic comedy). This could suggest that Syracusan has a regular reflex ${ }^{*} r$ $>-\rho \alpha$-, and that $x \alpha \rho p \omega \nu$ was taken from another Doric dialect to become the form of the literary Koine. This dialect may have been Laconian, given that the oldest literary attestation of $x \alpha \dot{\rho} \rho \omega \nu$ is in Alcman, and given the prestige of his poetry. According to Hinge (2006: 38 ), a Laconian context is also suggested by two other sources for xáppoves.

If this is correct, Laconian would agree with the Spartan colony Thera (and with Cretan) in having the vocalization $-\alpha p$-, and differ in this respect from

36 A first member Kp $\alpha \tau \alpha l-$ is attested in inscriptions from various regions. The name Kp $\alpha \tau \alpha \mathrm{l}-$ $\mu \varepsilon \dot{v} \eta \varsigma$ occurs in Athens, Euboea, Ionia, and in an early example (SEG 22.345, 6th c.) that is perhaps from an Achaean colony in Magna Graecia; Kp $\alpha \tau \alpha$ ß

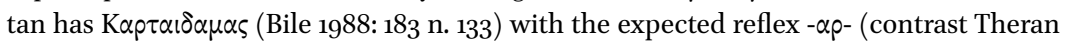

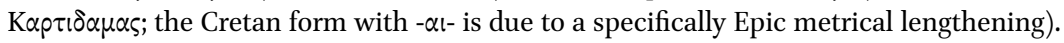
In section 5.2.11, I propose that Kaptl- < ${ }^{*} k r t h_{1}-i$ - is the old compounding allomorph of

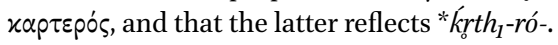

37 For further attestations of $\chi \dot{\alpha} \rho p \omega \nu$, see $L S J$ S.v. and Forssman (1980: 194 n. 77).

38 See section 5.2.1. 
at least Syracusan (colony of Corinth). ${ }^{39}$ The occurrence of $x \alpha$ a p $\omega \nu$ in the two Syracusan poets Epicharmus and Sophron is not decisive for the development

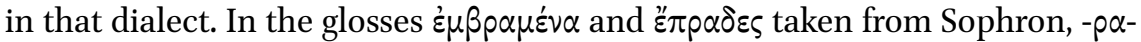
may well be the genuine Syracusan (and therefore Corinthian) vocalization. ${ }^{40}$ Once again, all this is quite uncertain in view of the limited evidence.

\subsubsection{The Dialect of Elis}

There is some evidence for ${ }^{*} r>-\rho \alpha$ - also in the dialect of Elis, but it is slight. Most of the evidence in the recent dialectal grammar by Minon (2007) cannot be used to determine the reflexes of ${ }^{*} r$. For instance, it is impossible to determine whether $\theta$ appev (Minon $\mathrm{N}^{\mathrm{o}}$ 20.1) derives from ${ }^{*} t^{h}$ ers- or from ${ }^{*} t^{h_{r} s-}$, because - $\alpha \rho$ - may reflect ${ }^{*}-\varepsilon \rho$ - in Elis. As in other dialects, the verb $\gamma \rho \alpha \dot{\varphi} \varphi \omega$ and its derivatives appear (cf. section 9.2.2 for further discussion). The value of most Elean glosses in Hesychius (discussion in Minon 2007:549-560) is unclear.

There is, however, one good pair of candidates to show the regular reflex

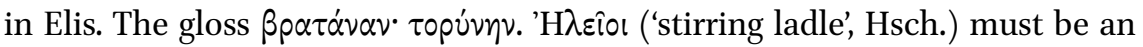
instrument noun in - $\alpha$ vi derived from a root *urat-. ${ }^{41}$ In view of the meaning 'stirring ladle', a derivation from the root *uert- 'to turn' suggests itself. The

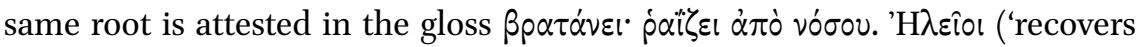
from illness', Hsch.), if we suppose that the meaning developed from "turns better" (Minon 2007: 554). This present formation in - $\alpha v \omega$ probably presupposes the existence of a thematic aorist *urate/o- (cf. $\beta \lambda \alpha \sigma \tau \dot{\alpha} \nu \omega$ : $\beta \lambda \alpha \sigma \tau \tau \varepsilon \hat{\imath} \nu, \dot{\alpha} \mu \alpha \rho-$ $\tau \dot{\alpha} \nu \omega$ : $\alpha \mu \alpha \rho \tau \varepsilon \hat{\nu})$ ). It is conceivable that a causative $s$-aorist *uert-s- (presupposed

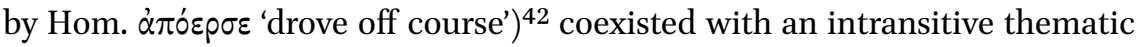
aorist *urt-e/o-in Proto-Greek. If so, the latter form developed into *urate/o- in Elean, and the noun $\beta p \alpha \tau \alpha \dot{\alpha} \alpha$ was also built on the zero-grade root allomorph.

If these two glosses are considered reliable evidence, ${ }^{*} r$ may have yielded $-\rho \alpha$-in Elis even after a labial glide. The disagreement with the treatment in Cretan would be remarkable: the latter dialect has the outcome - $\alpha \rho-$, and probably -op- after labials. However, since the evidence comes from just two glosses, we

39 The reflex - $\alpha \rho$ - was perhaps also regular in Argolic, given forms like $\varphi \alpha p \xi$ ५५ (on which see section 3.2.4 and 9.2.3).

40 I have found no relevant examples in the evidence for non-Attic vase inscriptions (Wachter 2001).

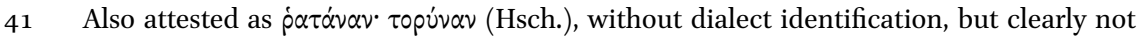
from Ionic-Attic.

42 As argued by Forssman (1980), in Ionic-Attic this root may be reflected in Homeric êppw 'to be lost' < *uert-ie/o-. The verb is attested in many dialects (in Elean as fappw, with secondary lowering of $e r$ ). 
must be careful. It must also be taken into account that the word for 'drachm' is attested in Elis (Minon 2007:355): several times as $\delta \alpha p \chi \mu \alpha$ and once as $\delta \alpha p X \nu \alpha \varsigma$, possibly reflecting a pre-form ${ }^{*} d_{0} k^{h} m n \bar{a}-{ }^{43}$ However, the word for 'drachm' could well be an inter-dialectal loan. Under these conditions, it would not be wise to base any firm conclusions on the evidence at our disposal. ${ }^{44}$

One epigraphic form from Elis is highly relevant for the development of *!: $\alpha$ F $\lambda \alpha v \varepsilon \bar{\varsigma} \varsigma$ 'completely, all together' (Minon $\mathrm{N}^{\mathrm{o}} 4.4$ and 8.3). The same form

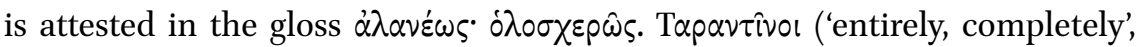
Hsch.), proving that this form is old in West Greek. As I will argue in section 10.6, these forms show that ${ }^{*}$ yielded $-\lambda \alpha$ - in Elean and Laconian even before nasals. Moreover, since the Cretan outcome may have been - $\lambda_{0}$ - after a labial consonant (cf. sections 10.3.1 and 10.6.1), it is possible that Proto-West-Greek preserved not only ${ }^{*} r$, but also $*$ l.

\subsubsection{The Dialects of the Argolid}

The evidence for the development of the syllabic liquids from Western and Eastern Argolic is presented in full detail by Nieto Izquierdo (2008: $145^{-15^{1}}$ and 380-381). It comprises the following forms:

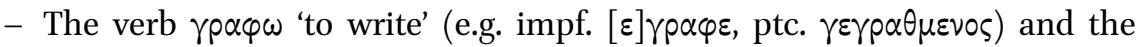
derivative $\gamma \rho \alpha \theta \mu \alpha$ / $\gamma \rho \alpha \sigma \sigma \mu \alpha$ letter' < *grap ${ }^{h} m a ; 45$

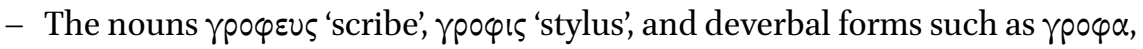
$\alpha \gamma p \circ \varphi \alpha, \varepsilon \gamma p \circ \varphi \alpha, \sigma u \gamma p \circ \varphi \circ \varsigma$, etc. (see section 9.2.2 for further analysis, especially of the $o$-vocalism);

- WArg. $\varepsilon \xi \sigma \tau p \alpha \varphi \varepsilon \tau \alpha l$ (Tiryns, SEG 30:380, no. 6.1, ca. 6оо-55о вСЕ(?)) corre-

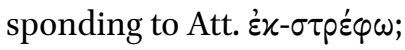

- Epid. $x p \alpha \mu \alpha \sigma \alpha \mathrm{l}\left(I G \mathrm{IV}^{2}, 1122.3\right.$, са. 320 в СE) corresponding to Att. $x \rho \varepsilon \mu \alpha \dot{\sigma} \sigma \alpha l$ 'to hang';

- The root $\sigma \tau p \alpha \tau$ - 'army' in $\sigma \tau p \alpha \tau \eta \alpha$ 'army, expedition' (Del. ${ }^{3} 84$, Tylisos, 46o-

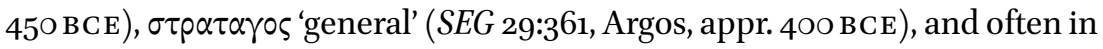
personal names;

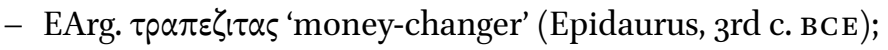

43 All the relevant inscriptions are dated to slightly before or after 500 BCE, so it is impossible to tell whether the form with $-\mu$ - or $-\nu$ - is older.

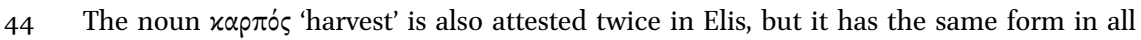
dialects where the word appears. Therefore, we cannot be certain that it reflects PGr. *krpó-.

45 With Lejeune (1972: 76 ) and against Nieto Izquierdo (2008: $381-382$ ), I prefer to view Arg. $\gamma p \alpha \theta \mu \alpha$ and $\gamma \varepsilon \gamma \rho \alpha \theta \mu \varepsilon v \circ \varsigma$ as due to dissimilation of ${ }^{*}-p^{h} m$ - at a morpheme boundary. As Nieto Izquierdo shows, attestations of the Koine form $\gamma p \alpha \mu \mu \alpha$ are later than those of $\gamma p \alpha-$ $\theta \mu \alpha, \gamma \varepsilon \gamma \rho \alpha \theta \mu \varepsilon v \circ \varsigma$ and $\gamma \rho \alpha \sigma \sigma \mu \alpha$. 


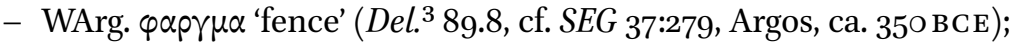

- EArg. $\varphi \alpha p \xi i v$ 'fence' (Epidaurus, IG IV $\mathrm{IV}^{2} 1102 \mathrm{~B}, \mathrm{l}$. 75, 400-350 BCE);

- EArg. $\varphi \alpha p \chi \mu \alpha \tau \alpha$ 'id.' (Epidaurus, ibid. l. 253);

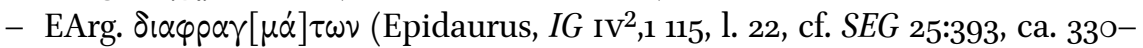
3ООВСE).

The forms with a root $\varphi \alpha p \chi$ - have older attestations than $\delta \alpha \varphi \rho \alpha \gamma[\mu \dot{\alpha}] \tau \omega \nu$; hence the latter must represent a Koine form. This is confirmed by the unassimilated root-final stop of $\varphi \alpha p \chi \mu \alpha \tau \alpha$ in Epidaurus. Likewise, the form $\tau p \alpha \pi \varepsilon \zeta \tau \tau \alpha \varsigma$ may well be a Koine form, as it is attested relatively late and is a normal word in the Koine. Both $\gamma \rho \alpha \dot{\varphi} \varphi \omega$ (and derivatives) and forms with $\gamma p \circ \varphi$ - are genuine Argolic dialect forms, and the same probably holds for $\varepsilon \xi \sigma \tau p \alpha \varphi \varepsilon \tau \alpha l, x p \alpha \mu \alpha \sigma \alpha l$ and the forms with $\sigma \tau p \alpha \tau-$.

With these reductions in mind, it appears that Argolic has a reflex - $\alpha p$ - in $\varphi \alpha \rho \xi \nu, \varphi \alpha \rho \gamma \mu \alpha, \varphi \alpha \rho \chi \mu \alpha \tau \alpha$, as against - $\rho \alpha-$ in $\varkappa \rho \alpha \mu \alpha \sigma \alpha l, \gamma p \alpha \varphi-, \sigma \tau p \alpha \tau$ - and $\sigma \tau p \alpha \varphi-$.

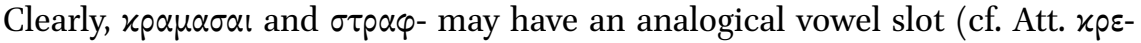
$\mu \dot{\alpha} \sigma \alpha l, \sigma \tau p \varepsilon \dot{\varepsilon} \varphi \omega)$, and the same may be true of $\gamma p \alpha \varphi$ - (beside $\gamma \rho \circ \varphi$-). The reflex $\sigma \tau p \alpha \tau$ - cannot be analogical and therefore seems to prove a regular reflex - $\rho \alpha-$ in this dialect. However, it must be taken into account that all Greek dialects except for Cretan and Cyrenaean use the root $\sigma \tau p \alpha \tau$-, so some caution is in order. In the case of $\varphi \alpha \rho \xi i v, \varphi \alpha \rho \gamma \mu \alpha, \varphi \alpha \rho \chi \mu \alpha \tau \alpha$, much depends on the recon-

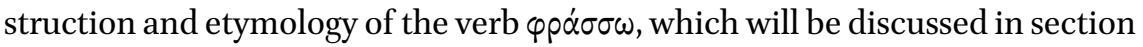
9.2.3.

Thus, no definite conclusion concerning the regular place of the anaptyctic vowel can be drawn for the dialects of the Argolid.

\subsubsection{Conclusion on the West Greek Dialects}

The only West Greek dialect for which we have clear-cut evidence is Cretan. In this dialect, ${ }^{*} r$ yields - $\alpha p$-, and perhaps -op-after a labial consonant. There is slight evidence for a regular outcome $-\rho \alpha$ - in glosses from Elis and Syracuse, and for - $\alpha p$ - in Theran and Cyrenaean onomastic material. If the evidence for $-\rho \alpha$ - in the former two dialects is taken seriously, the divergence with Cretan would show that Proto-West Greek, and even Proto-Doric, kept ${ }^{*} r$ intact. If so, the vocalization may well have taken place during the Dorian migrations in the early Dark Ages. The different reflexes can be ascribed to the different situations of linguistic contact between speakers of West Greek and the earlier populations in the regions where they settled. 


\subsection{The Aeolic Dialects}

Our ability to reconstruct the prehistory of the Aeolic dialects is hampered in several respects. The most abundant sources of examples are the Lesbian poets Sappho and Alcaeus, but the status of this evidence is not always clear, because a number of forms may be hyper-Aeolic or of epic origin. ${ }^{46}$ Epigraphic material from Lesbian has already undergone considerable Koine influence at a time when inscriptions start to become numerous. Most Thessalian evidence is also late and much of it suffers from the same problem. Boeotian is a mixed dialect which contains many West Greek features. Finally, a large part of the evidence consists of personal names, where influence of other dialects or even the poetic language is a factor to be reckoned with.

In addition to these factual problems, there are practical ones. As yet, there is no comprehensive grammar of the Thessalian dialects, nor of Boeotian. ${ }^{47}$ The generative description of the Aeolic dialects by Blümel (1982) is of some use, but has no separate treatment of the reflexes of ${ }^{*} r$.

Notwithstanding all these problems, the combined evidence of our sources does allow us to draw a definite conclusion: the regular reflex was -po-, without further conditioning, in all Aeolic dialects. I will now first review the epigraphic evidence, and after that turn to the extant fragments of Sappho and Alcaeus. Homeric words with -po- will not be discussed here, but in chapter 7 , as their Lesbian or Aeolic provenance is not certain.

\subsubsection{The Numerals in the Aeolic Dialects}

Let us start with the variation between $\rho \alpha / \alpha \rho$ and $\rho o / o p$ in numeral forms in the Aeolic dialects. The attestations are conveniently listed in Blümel (1982: 271275). Concerning the variations in form, he notes that "die Einzelheiten der Abgrenzung zwischen phonologischen und morphologischen Ursachen sind noch nicht übereinstimmend geklärt" (Blümel 1982: 52-53).

In section 2.7, it was proposed that the numerals in Aeolic dialects underwent analogical modifications similar to those taking place in other dialects. For instance, the Boeotian forms $\pi \varepsilon \tau \rho \alpha \tau \circ \varsigma$ and $\pi \varepsilon \tau \rho \alpha$ - are usually explained as contaminations of original Aeolic * $\pi \varepsilon \tau p \circ \tau \circ \varsigma,{ }^{*} \pi \varepsilon \tau p o-$ with Attic or West Greek forms (e.g. Waanders 1992: 379), but it is more likely that they underwent the

46 The problems are clearly stated in Ruijgh (1961: 194). Cf. generally on these issues Hooker (1977) and Bowie (1981).

47 A grammar of Thessalian by García Ramón and Helly is still in preparation. Vottéro (1998, 2001) announced the publication of a book on the phonetics and phonology of Boeotian, but to my knowledge, this has not yet appeared. 
same analogical influence of higher numerals (such as $\varepsilon \pi \tau \alpha-, \delta \varepsilon \kappa \alpha-$ ) that yielded Ionic-Attic $\tau \varepsilon \tau \rho \alpha$-. Another parallel for this influence is Arcadian $\pi \varepsilon \mu \pi \circ \tau \circ$ ' $^{\prime}$ fifth',

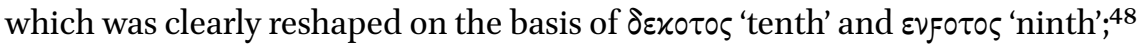
Note that the forms $\delta \varepsilon x \alpha \tau \circ \varsigma$ and $\varepsilon v \alpha \tau o \varsigma$ are actually attested in Boeotian inscrip-

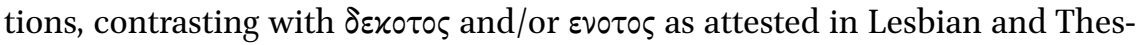
salian inscriptions.

The same explanation can be applied to the Thessalian forms $\pi \varepsilon \tau p o-\varepsilon \tau \eta p$

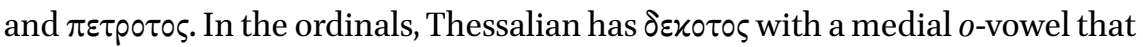
may have spread from 'nine' or even 'eight' (cf. the shortened form oxт० in Boeot.

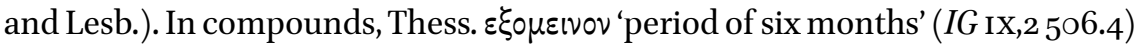
is another clear instance of the spread of -o- as a linking vowel, comparable to the spread of $-\alpha$ - in Ionic-Attic $\pi \varepsilon v \tau \alpha-, \bar{\varepsilon} \xi \alpha-($ after $\dot{\varepsilon} \pi \tau \alpha-,, \ldots, \delta \varepsilon \kappa \alpha-) . .^{49}$ Therefore, it is not completely certain that Thess. $\pi \varepsilon \tau$ po- is the regular outcome of ${ }^{*} k^{w} e t r-$ before consonants.

\subsubsection{Epigraphic Evidence (Boeotian, Thessalian, Lesbian)}

I start from the forms given in the dialect grammars. ${ }^{50}$ Most discussions of the Boeotian reflex of ${ }^{*} r$ cite just two forms: the compound elements $-\sigma \tau$ t and Bpox-, which are widespread in proper names from the region. ${ }^{51}$ Importantly, the word for 'army; campaign' does not only appear in names, but also in the verbal form $\varepsilon \sigma \sigma \tau p o \tau \varepsilon v \alpha \theta \eta$ (IG VII, 3174 and passim). ${ }^{52}$ Boeotian also has instances of $a$-vocalism such as $\pi \varepsilon \tau p \alpha$ - and $\pi \varepsilon \tau p \alpha \tau o \zeta$, but as we have just seen, these forms may be analogical. Thus, although Boeotian does not offer much

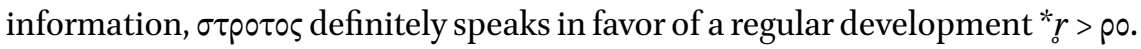

As for Lesbian, a first important piece of evidence is $\sigma \tau p o \tau \alpha \gamma o \varsigma$, denoting a magistrate. As Hodot (1990: 56) remarks, this title is in the process of being replaced by $\sigma \tau p \alpha \tau \alpha \gamma \circ \varsigma$, a hybrid form consisting of dialectal (- $\alpha \gamma \circ \varsigma)$ and Koine

48 The Arcadian form Evfotos has recently come to light on an archaic festival calendar (Carbon-Clackson 2016).

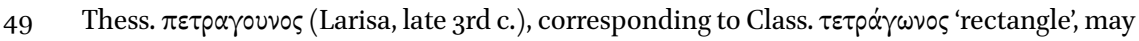
be ascribed to Koine influence.

50 Bechtel (1921-1924, I: 242-243), Thumb-Scherer (1959); Blümel (1982); Hodot (1990).

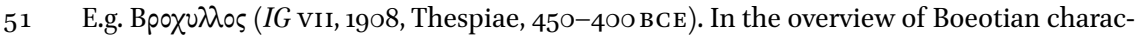
teristics by Van der Velde (1929), the attestations of these forms are presented per locality; see also García Ramón (1975: 62-63). A third form usually mentioned in this connection is

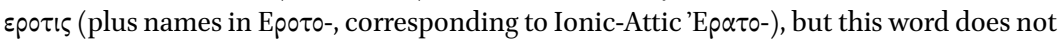
derive from a pre-form with ${ }^{*} r$, and the difference in vocalism must have another cause. The alleged PN $\Theta p] 0 \sigma 10 v \sigma \tau p o \tau \circ \varsigma$ is based on a false reading (see Masson 1972: 293).

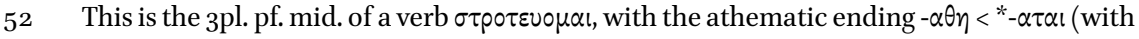
secondary $-\theta$ - and monophtongization of $\alpha$ ). 
$(\sigma \tau p \alpha \tau$-) elements. The real Koine form $\sigma \tau p \alpha \tau \eta \gamma o ́ s$, with Ionic $-\eta-$, never occurs in Lesbian inscriptions. Other forms derived from this lexeme introduced $a$ vocalism much earlier, e.g. $\sigma \tau p \alpha \tau \varepsilon \downarrow \alpha$ (Hodot, NAS o1, 4th c.). In the literary

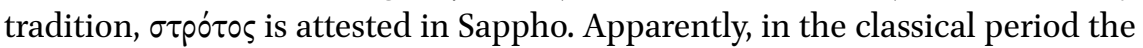

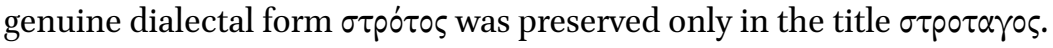

The second important epigraphically attested form is $\alpha \mu \beta p o \tau \eta \nu$ 'to transgress' (IG XII,2 1.5), which again has a counterpart in literary Lesbian, $\alpha \mu \beta p o \tau \varepsilon$ (on which see below). There is no further relevant evidence: the root $\gamma \rho \alpha \varphi$ - (in forms like $\alpha \nu \tau i \gamma p \alpha \varphi \varepsilon v \varsigma, ~ \gamma p \alpha \varphi \eta v)$ is well-attested, as it is in all other dialects, but it need not have contained ${ }^{*} r$. The attestation of $\sigma \alpha p \xi$ (Hodot 199o, MAT o3.11 and 05.16, 21, end of $3 \mathrm{rd}$ c.) is relatively late, so it could be a loanword from Ionic. In conclusion, both $\sigma \tau p \circ \tau \alpha \gamma \circ \varsigma$ and $\alpha \mu \beta \rho \circ \tau \nu \nu$ are trustworthy evidence for the development ${ }^{*} r>$ po in Lesbian.

In Thessalian, the root * $m r k k^{h}$ 'short' is attested as a personal name Bpoxvs ( $I G$ IX,2 46o.13, Krannon, Pelasgiotis, 2nd c.) and in its older form in the female

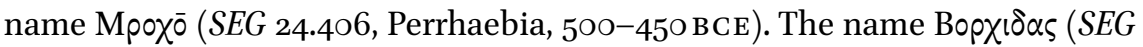
26, 672.32, Larisa, Pelasgiotis, early 2 nd c.) may be due to a later metathesis, if it is indeed related. As we have seen, Bpoxv- is also found as an onomastic element in Boeotian.

A regular Thessalian outcome - $\rho$ - is often thought to be supported by $\pi \varepsilon \tau$ po$\varepsilon \tau \eta p 1 \delta \alpha$ (RPh. 1911, 123.26, Larisa, 1st c.). Since this form has an unexpected spelling $\langle\eta\rangle$ of the outcome of ${ }^{*} \bar{e}$ (which is otherwise spelled as $\langle\varepsilon l\rangle$ in this dialect), and since the inscription has a number of Koine features, the evidential value of this form used to be questioned. Later, however, the form $\pi \varepsilon \tau p o-$ has been confirmed by $\pi \varepsilon \tau p \circ \varepsilon \tau \varepsilon i p ı \delta \alpha$ (SEG 17.288 passim, Larisa, 1st c. BCE or later) and by the ordinal $\pi \varepsilon \tau p o \tau o \varsigma$ (SEG 43.311, Skotoussa, Pelasgiotis, early 2nd c.).

Nevertheless, it is not completely certain that these forms contain a reflex of * $r$ : we must take into account that Myc. qe-to-ro- and Class. $\tau \varepsilon \tau p \alpha-$ may be remodellings of the older form PIE ${ }^{*} k^{w} e t r u$-based on the compositional form of 'ten-' (see sections 2.7 and 3.3.1). The same could be true of Thess. $\pi \varepsilon \tau$ po-, as a linking vowel -o- also occurs in Thess. $\varepsilon \xi \circ \mu \varepsilon i v o v$ 'period of six months' (IG IX,2 506.4). Moreover, an $o$-vowel is attested for the ordinals $\delta \varepsilon$ xotos 'tenth' (at

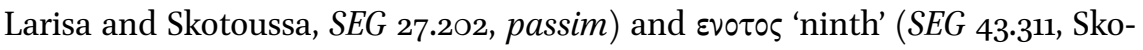
toussa). Therefore, given the model of the 1st compound members $\pi \varepsilon \tau p o-, \varepsilon \xi 0-$, it cannot be completely excluded that an older form ${ }^{*} \pi \varepsilon \tau 0 \rho \tau$ ऽ was changed into $\pi \varepsilon \tau$ трото५. .3 
Another Thessalian piece of evidence has been adduced by García Ramón (1999: 11-13): he argues that $\Theta p o \sigma i \alpha$, an epiclesis of Artemis at Atrax and Larisa in the Hellenistic period, is derived from ${ }^{*} \theta$ pó $\sigma \varsigma \varsigma<{ }^{*} d^{h}{ }^{h}$-ti- 'support. ${ }^{54}$ In his opinion, $\Theta p o \sigma i \alpha$ refers to Artemis in her function as a supporter and protector of youngsters in a rite of initiation. An alternative derivation from the root * $d^{h}$ ers- of $\theta p \alpha \sigma u ́ \varsigma$ has been proposed (see e.g. LSJ), but García Ramón objects that this adjective was continued in Thessalian as $\theta$ epous (with full grade root) on account of a different epiclesis, $A \theta \alpha \nu \alpha \Theta \varepsilon p \sigma \nu{ }^{55}$ In either case, whether the

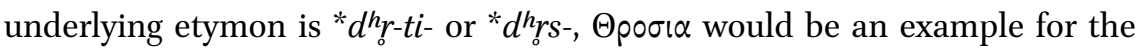
vocalization of * $r$. Being a name, however, the form must be handled with due caution.

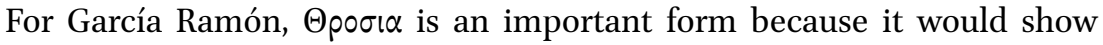
that the $o$-colored reflex in Thessalian occurs not only in contact with labial sounds. ${ }^{56} \mathrm{He}$ also refers to the (as yet unpublished) Thessalian form op $\sigma \varepsilon v$ 'male', which contains no initial digamma and derives from the zero grade also reflected in Hom. äpopv. I would add that, contrary to what is often stated, the ${ }^{*} r$ in $\pi \varepsilon \tau p o \tau o \varsigma$ did not stand in a labial environment either: the simplification *tur $>$ *tr took place early on (section 2.6).

We may conclude that there is secure evidence for $o$-coloring of the Thessalian reflex, but the regular vowel slot is less clear than in Boeotian or Lesbian. The only direct piece of evidence for -po- is the epiclesis $\Theta p o \sigma \alpha$. The names Mpox̄̄, Bpox ऽ may have a levelled vowel slot (PGr. * $m r e k^{h_{-}}$, cf. section 4.3.3), and for $\pi \varepsilon \tau \rho \circ \tau \varsigma \varsigma$ we cannot exclude that it was influenced by the compounding form $\pi \varepsilon \tau p o-$, which itself may have taken its $o$-vocalism from higher numerals.

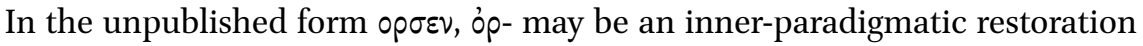

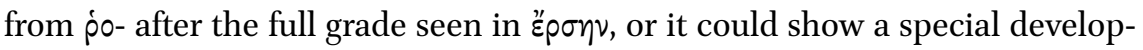
ment of ${ }^{*} r$ in word-initial position (see section 9.1.7 for further discussion).

Thus, although the evidence does not completely exclude -op-, the wordmedial reflex in Thessalian was most probably -po-, as in Lesbian and Boeotian.

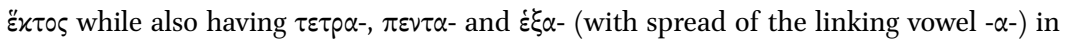
compounds. On Homeric $\tau \dot{\varepsilon} \tau p \alpha \tau \circ$ s, see section 6.8.4.

54 Cf. also García Ramón \& Helly (2007: 305-306).

55 In my view, this objection is not cogent. As García Ramón himself remarks, @epous is a substantivized feminine 'the bold one', "Her Boldness" of the archaic type i $\theta$ ú (f.) 'course' beside i $\theta \dot{s}$ (adj.) 'straight' (see Lamberterie 1990: 887-888). If the $u$-stem adjectives had root ablaut in Proto-Greek (see section 4.1.1), this substantivized form may have been derived from the full grade stem at an early date, before the adjective generalized the zero grade reflex.

$5^{6}$ "lässt sich der $o$-Vokalismus bei der Vertretung von ${ }^{*} r$ als nicht durch die phonetische Umgebung bedingt erkennen." (García Ramón 2007c: 106). 


\subsubsection{The Relation between Lesbian Lyric and Ionian Epic}

Linguistic evidence from the poems and fragments of Sappho and Alceaus is to be used with caution for more than one reason. As remarked above, this material may not only contain Ionic words with $a$-vocalism; it may also have undergone hyper-aeolicization at the hands of later editors or copyists. After the work of Lobel, it was thought for some time that Sappho composed her poems not in a literary dialect, but in the Lesbian vernacular (cf. the discussion in Bowie 1981: 6o ff.). In order to maintain this thesis, Lobel had to reject a number of Sapphic fragments as ungenuine, and to assume a large number of emendations in the other fragments. As Bowie remarks, however, some fragments that were declared non-Sapphic by Lobel had the same metre as others that he did consider genuine. Thus, Lobel's criteria for emending forms or rejecting entire fragments lacked a solid basis.

Since the monographs by Hooker (1977) and Bowie (1981), two things have become much clearer. First of all, there has been substantial Ionic influence on the language of Sappho and Alcaeus. This influence can be ascribed, to a large extent, to the epic tradition, but it is equally possible that vernacular Lesbian vocabulary used by Sappho and Alcaeus had been influenced by that of the neighboring Eastern Ionic vernaculars (Bowie 1981). Secondly, Sappho and Alcaeus used a literary dialect for their genre which had a tradition of its own, as follows from the meters they use. Aeolic lyric may owe part of its vocabulary and phraseology to this tradition, but it is unclear what exactly the Lesbian contribution was. ${ }^{57}$

The influence of Ionic on the language of the Lesbian poets was clearly substantial. In practice, it is often difficult to decide whether a given Ionic form is due to epic influence or to borrowing from the Ionic vernacular, but that is irrelevant for present purposes. ${ }^{58}$ Both Lesbian poets make use of a fair number of epic lexemes and grammatical characteristics, especially (though not exclusively) in poems with epic subject matter. Convincing cases of Ionic or epic influence include the following: ${ }^{59}$

57 In the words of Bowie (1981: 177), the lexicon of Sappho and Alcaeus "shares the characteristics and components of the poetic dictions of the other early Greek poets, both epic and lyric".

$5^{8}$ Bowie is reluctant to explain words that occur both in Lesbian poetry and in Homer as epicisms. The fact that a word is shared by Lesbian poetry and the epic language may mean two things. Either the word is inherited from an earlier, Common Greek poetic language, or one of the poetic languages borrowed the word from the other.

59 In what follows, fragment numbers refer to Voigt's edition of Sappho and Alcaeus (Voigt 1971). 
- the long vowel s-aorist subjunctive (e.g. $\varphi \alpha p \xi \omega \dot{\omega} \mu \varepsilon \theta \alpha$, Alc. 6.7), which is typical for Ionic-Attic;

- $\alpha \delta \varepsilon \lambda \varphi \varepsilon \dot{\alpha} \alpha$ 'sister' (Sapph., Alc.) < *ha-gwelphehā-, with a dental reflex of the labiovelar (Bowie 1981: 89-9o);

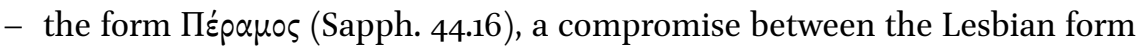

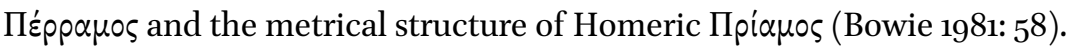

Bowie (1981: 137) further mentions as epicisms the forms $\pi \varepsilon p$ $\tau \alpha$ l, $\gamma \alpha \hat{i} \alpha$ (vernacular Lesbian $\gamma \hat{\alpha}$ ), $\hat{p} \hat{\gamma} \alpha$ (for Hom. $\dot{\rho} \varepsilon \hat{\alpha} \alpha$, contrast vernacular Les-

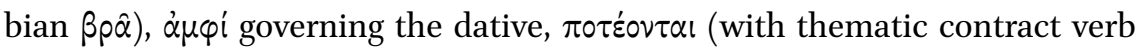
inflection), and $\dot{\varepsilon} \sigma \tau \varphi \varphi \hat{\varepsilon} \lambda(\xi \xi$ (velar flexion of the $s$-aorist). This list could easily be extended. ${ }^{60}$ As candidates to have been borrowed from spoken Ionic into the Lesbian vernacular, i.e. forms for which it is unnecessary to assume epic

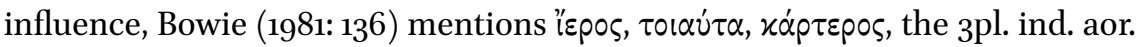

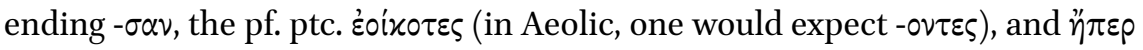
(enclitic $-\pi \varepsilon \rho$ is otherwise absent from Lesbian).

Like $\varphi \alpha \rho \xi \dot{\omega} \mu \varepsilon \theta \alpha$, a number of forms with $\rho \alpha / \alpha \rho<{ }^{*} r$ that are found in Sappho and/or Alcaeus may stem from Ionic (for a full list, see section 3.3.5 below). For this reason, I disagree with O'Neil (1971) and Wyatt (1971) that $\rho \alpha / \alpha \rho$ is the regular reflex in Lesbian under certain conditions.

\subsubsection{Evidence for o-vocalism in Literary Lesbian}

The only potential evidence for the reflex of *l is d́ó $\lambda \varepsilon \varepsilon \varsigma$ (Alc. 348.3) This form may be either an epicism or an instance of ${ }^{*} l>-0 \lambda$ - before nasals; see section 10.5.4 for further discussion. I will therefore focus on the reflex of ${ }^{*} r$.

The following forms from Sappho and Alcaeus, in alphabetical order, must be considered as potential evidence for -po- as a regular reflex (and -op-as analogical):

- $\beta \rho^{\prime} \chi \varepsilon(\alpha)(\text { Sapph. 31.7 })^{61}$

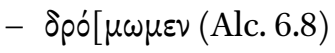

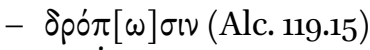

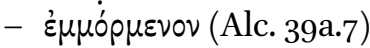

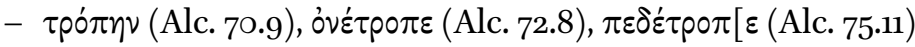

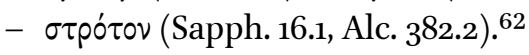

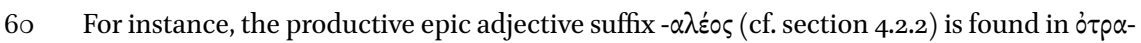

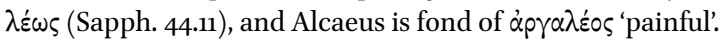

61 The form ] $\beta \rho \alpha \chi \eta$ [ in Alc. 300.9 (cited by O'Neil 1971: 24, but of unclear interpretation) need not belong here: it may be from a completely different lexeme, e.g. that of Hom. है $\beta p \alpha \chi \varepsilon$ 'resounded'.

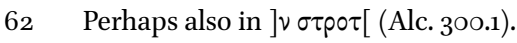


The following forms are well-attested in Epic Greek and can be analyzed as epicisms in Lesbian lyric. ${ }^{63}$ For this reason, they cannot be used as secure

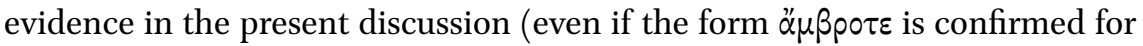
Lesbian by epigraphic evidence: see above):

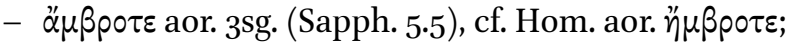

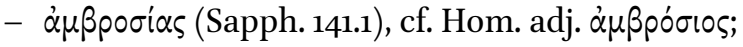

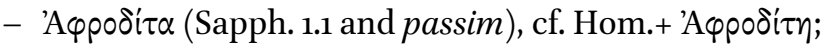

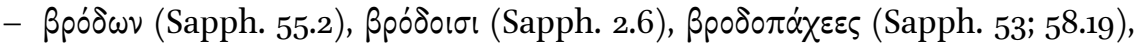

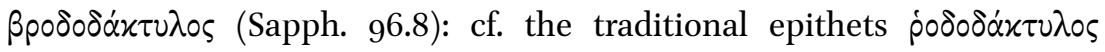
(Hom.+) and poó́ $\pi \eta \chi \cup \varsigma$ (Hes.+).

I also leave aside the following forms: ${ }^{64}$

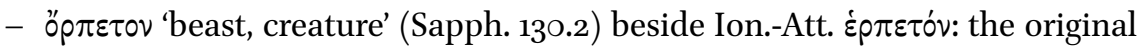
vocalism of the Lesbian form is unclear. In his monographic treatment of

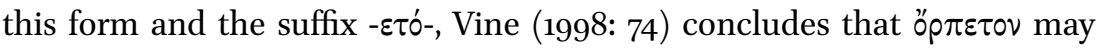
have been contaminated with a form *oj $\rho$ ó- 'creeper' that is perhaps also presupposed by oै $\rho \pi \eta \xi$ 'young shoot, sapling';

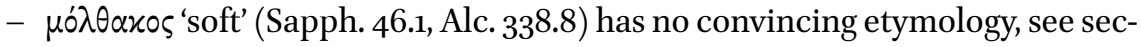
tion 10.1.7;

- the forms $\gamma p o ́ \pi \pi \alpha \tau \alpha$ and $\gamma p o ́ \pi \tau \alpha$ (Balbilla) are probably hyper-Aeolisms in view of the universal occurrence of $\gamma \rho \alpha \varphi$ - in Lesbian inscriptions;

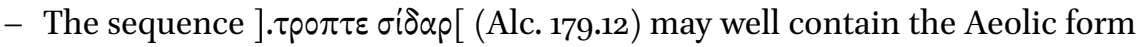
corresponding to epic $\dot{\alpha} \sigma \tau \rho \dot{\alpha} \pi \tau \omega$ 'to flash (of lightning)', but the reconstruction of this etymon is uncertain;

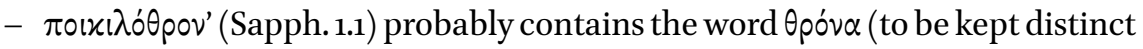
from $\theta$ póvos 'throne'): cf. the discussion in section 2.5.2.

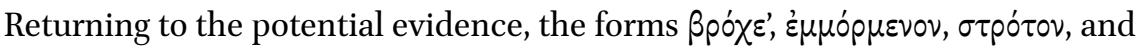
the thematic aorists $\delta \rho \mu \varepsilon \varepsilon / 0-, \delta \rho \circ \pi \varepsilon / 0-$, and $\tau \rho \circ \pi \varepsilon / 0$ - cannot be due to epic influence, as Homer attests these forms in a shape with - $\rho \alpha$ - or $-\alpha p$ - These words with a reflex -po- were at home in the Lesbian poetic tradition, and they probably entered this tradition as Lesbian vernacular forms. Indeed, the following forms with -po- are backed up by epigraphic evidence from Lesbian or other Aeolic dialects:

- $\alpha \mu \beta p o \tau \varepsilon(\alpha \mu \beta p o \tau \eta \nu ~ I G ~ X I I, 2$ 1.5);

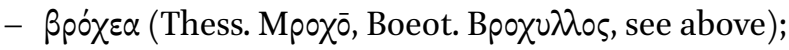

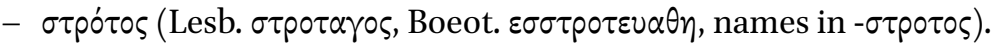

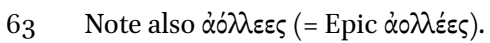

64 On övorpos (Sapph.), see the next section. 


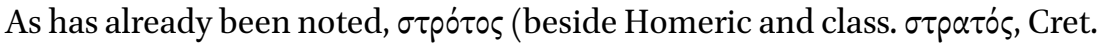
$\sigma \tau \alpha$ T $0 \varsigma$ ) shows that the $o$-colored reflex was regular also in a non-labial environment.

What does this evidence teach us about the regular place of the epenthetic vowel in Lesbian? In order to answer this question, let us now discuss some of the attested forms in more detail:

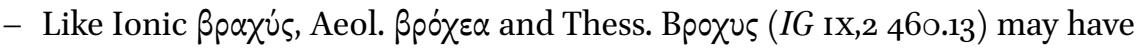
leveled the old full grade slot (attested in Lat. brevis; cf. section 4.1.1 and 4.3.3).

- There are three examples of thematic aorists with $o$-vocalism in Lesbian poetry. Of these, $\tau$ pó $\pi \eta \nu$ is well-attested (prefixed forms o $\nu \varepsilon \dot{\tau} \tau \rho \circ \pi \varepsilon, \pi \varepsilon \delta \varepsilon \dot{\tau} \tau \rho \pi \varepsilon$ ); besides, $\delta \rho o ́ \pi[\omega] \sigma \nu$ and the restored form $\delta \rho o ́[\mu \omega \mu \varepsilon \nu$ also clearly speak in favor of $o$-vocalism. Clearly, the vowel slot of $\tau p \circ \pi$ - could be analogical: cf.

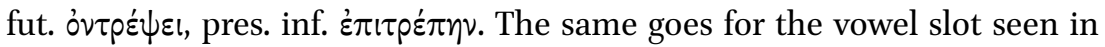

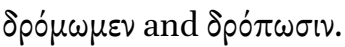

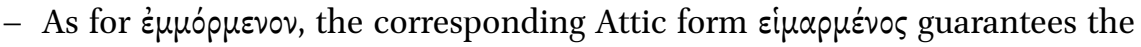
antiquity of the formation, a middle perfect * $h e-h m r$-toi with zero grade root.

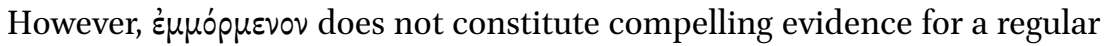
alternative treatment ${ }^{*} r>-0 p$ - in Lesbian, because in Homer we also find the older active perfect है $\mu \mu \rho p \varepsilon$ (normally viewed as an Aeolism). Since the substitution of middle for older active perfect forms is widespread (cf. $\tau \varepsilon \tau \tau-$

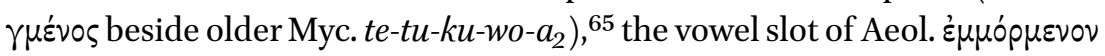
may have been influenced by that of है $\mu \mu о p \varepsilon$.

The remaining forms clearly show that the regular Lesbian outcome of ${ }^{*} \mathrm{Cr} T$ was CroT-. The clearest instances are $\alpha \mu \beta p \rho \tau \varepsilon$ (epigraphic $\alpha \mu \beta p o \tau \eta \nu), \sigma \tau p o ́ \tau o \varsigma$

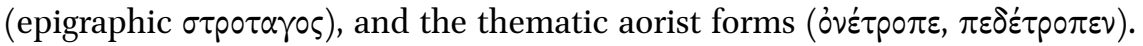
The epenthetic vowel regularly appears after the liquid in the isolated forms

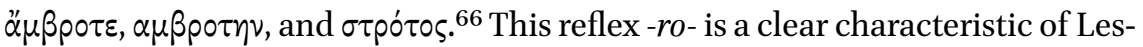
bian and Aeolic generally. In this respect the Aeolic dialects differ from Mycenaean, and also from Arcadian, where the regular reflex was -or- (as we shall see below).

\subsubsection{Evidence for a-vocalism in Literary Lesbian}

The following list contains all potential evidence for an $a$-colored reflex of ${ }^{*} r$ and ${ }^{*}$ in literary Lesbian:

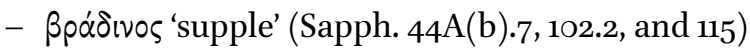

- Ëapos 'spring' gen. (Alc. 296b.3), contracted ท̂pos (Sapph. 136, Alc. 367)

65 On the relation between middle-passive and active perfect forms and the replacement of active perfects, see Van Beek and Migliori (2019).

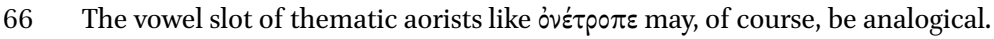


- xapoía 'heart' (Sapph. 31.6, Alc. 207.9)

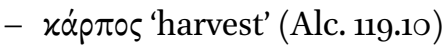

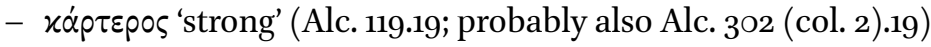

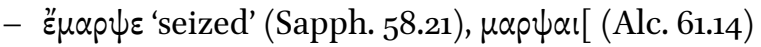

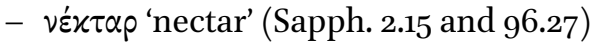

- övap 'dream' (Sapph. 134)

- örnap 'benefit' (SLG, S286(2).10)

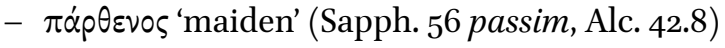

- $\tau \dot{\alpha} \beta \beta \eta \mu$ 'to be scared' (Alc. 206 and 302.12)

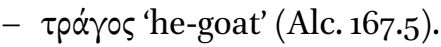

A number of these forms must be left out of consideration: है $\mu \alpha \rho \psi \varepsilon$ and $\pi \dot{\alpha} p \theta \varepsilon-$ vos are pan-Greek forms without a convincing etymology (cf. section 9.7.2). For $\tau \rho \alpha$ ros, a pre-form with ${ }^{*} r$ is uncertain as we might be dealing with a secondary zero grade beside the present $\tau p \omega \gamma \gamma \omega$, from a root ${ }^{*} \operatorname{treh}_{3} g$ - (section 9.1.4). The epic verb $\tau \alpha \rho \beta \varepsilon$ है was also utilized in Lesbian poetry and in the Attic tragedians; its $a$-vocalism may point to an Ionic-Attic origin, if the derivation from a zero

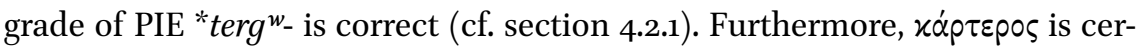
tainly a borrowing from Ionic, whether from the vernacular or from Epic Greek; see the arguments adduced by Bowie (1981: 99-100). ${ }^{67}$ It is also conceivable that Aeol. xáp $\pi \circ \zeta$ is of epic or Ionic origin, but this word is difficult to evaluate in any case, as it has the same form in all dialects where it is attested.

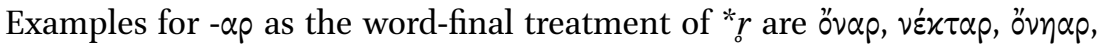
and हैapos. Given that it displays the change ${ }^{*} \bar{a}>\eta$, oै $\eta$ $\alpha p$ must be a borrowing from Ionic. ${ }^{68}$ The three other forms also occur in Homer, and especially

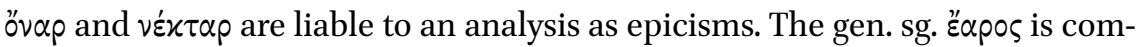
monly thought to have been built on the nom. हैap (Hom.+) < PIE *ues-r. The two instances of contracted ทेpos may be of Ionic origin, and uncontracted हैapos may be an epicism. Thus, there is no direct evidence for the Lesbian vernacular development of ${ }^{*} r$ in word-final position. ${ }^{69}$

67 Bowie's analysis, however, is misguided to some extent by O'Neil's (1971) poor linguistic treatment of the evidence.

68 On Aeol. $\eta$ corresponding to Ionic $\varepsilon$ เ in prevocalic position, see Slings (1979; p. 251 n. 36 on örnap).

69 Ruijgh (1961) proposed that the regular Lesbian (and also Achaean) outcome of ${ }^{*} r$ in

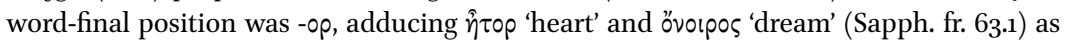
examples. In fact, the attestation of $\hat{\eta} \tau o p$ in Lesbian (Alc. fr. 6.20) is highly uncertain (cf. the edition by Voigt), so that only the Sapphic form övolpos would remain as an indirect piece of evidence for the Lesbian development. This form has been compared to Arm. anury 'dream' and derived from *onōr-io-, a reconstruction that is not without problems. However, the idea that ovo opos is a contamination between oैveıpos (the normal Greek form) and Lesb. *ovvop < *onr deserves full consideration. Cf. section 9.5 on word-final * ${ }_{-} r$. 
Two remaining forms require a more elaborate discussion. Both Lesbian

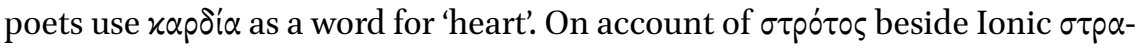

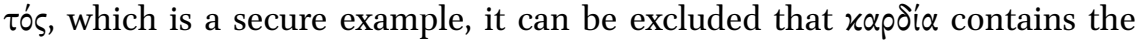
regular reflex of * $r$ in Lesbian. Since $x a p \delta i n$ was certainly the regular vernacular form in neighboring Ionic dialects, we must assume that this form was borrowed into Lesbian. There is another possible, but rather uncertain attestation $x$ ] op $\delta^{\prime} \alpha \nu$ (Alc. 130A.4, initial $x$ - suggested by Diehl). ${ }^{70}$ If this is indeed the correct reading, it could be a hyper-Aeolic form, as the vocalization -op- would be at odds with the otherwise clear evidence for -po- as the Lesbian reflex.

The adjective $\beta p \alpha \dot{\delta} t v o s$ occurs three times in Sappho, and its $\beta p$ - certainly represents earlier *ur- (see the discussion in Bowie 1981: 80-84). ${ }^{71}$ The word has two main types of referent: (1) soft or supple body parts of women, e.g. feet, hands, cheeks, and also Aphrodite herself; (2) shoots, branches, and a whip that are 'supple, tapeable'. An etymological connection with Ved. vrad 'become soft' could therefore be envisaged, but this remains uncertain as the suffixation in - เvos remains without a good parallel. ${ }^{72}$ There are two options to explain - $\alpha \alpha-$ in this clearly poetic word. First, it is conceivable that $\beta p \alpha \dot{\delta}$ เvos stems from the Ionian epic tradition. Secondly, since $\beta p \alpha \dot{\delta}$ ivos has no secure etymology, it can be argued that a pre-form with ${ }^{*} r$ is not ascertained. In this case the word could be genuine Lesbian or belong to the Aeolic poetic tradition.

\subsubsection{Evidence for Aeolic o-vocalism in Ancient Grammarians}

As various previous authors have noted, much of the evidence from the ancient grammatical tradition cannot be relied upon. In many cases, there is no dialect

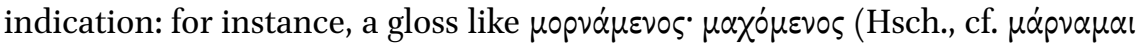
'to fight') need not be Aeolic, but could instead stem from Arcadian or Cyprian.

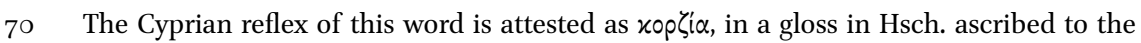
Paphians (see section 3.4.1).

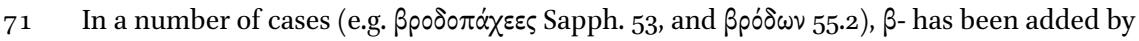
modern editors. In all three instances of $\beta p \alpha \dot{\delta}$ vvos, however, the mss. or papyri have initial $\beta$ - (reflecting digamma). Bowie criticizes Hooker's view (1977:28) that the $\beta$ - was a device to indicate that a short syllable was lengthened due to prevocalic initial $\dot{\rho}$-. In fact, only in half of the cases in Sappho does the $\beta p$ - close a final syllable that is short by nature (thus in öp $\pi \alpha \varkappa$ ı $\beta \alpha \delta i v \omega$ Sapph. 115; in Alcaeus, both cases of $\beta p$ - generate a heavy syllable). Bowie thinks that words spelled with $\beta p$ - are poetic archaisms of Lesbian: they preserve a reflex of * $u$ - insofar as this was metrically useful, while in the vernacular, *ur-had already developed to $r$ - by the time of Sappho.

72 See Chantraine (1933: 200-201) for the suffix -inó-, and Mayrhofer (EWAia s.v. VRAD) for

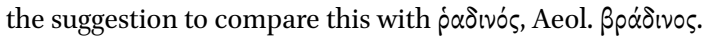


In other cases, the sources of the ancient grammarians cannot be deter-

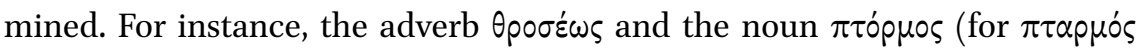
'sneeze') are cited as 'Aeolic' in the Compendium $\pi \varepsilon p i ~ \delta 1 \alpha \lambda \varepsilon \dot{\varepsilon} \tau \tau \omega \nu$ attributed to Johannes Grammaticus, and they do not contradict the conclusions obtained so far: $\theta p \circ \sigma \varepsilon \dot{\varepsilon} \omega \varsigma$ has the expected Aeolic reflex of ${ }^{*} r$, and if $\pi \tau$ óppos is a real form, various accounts are conceivable. ${ }^{73}$ The middle perfect forms $\tau \dot{\varepsilon} \tau o p \theta \alpha$, $\mu \varepsilon \dot{\varepsilon} \mu \circ-$ $\theta \alpha \mathrm{l}$ and $\varepsilon^{\varepsilon} \varphi \theta_{0} \theta_{\alpha \mathrm{l}}$ (wrongly referred to as 'Homeric' by O'Neil 1971: 26) are cited as Aeolic in (pseudo-)Herodian's On Iliadic Prosody $67 .{ }^{74}$ If such forms indeed once existed, the analysis of $\ddot{\varepsilon} \varphi \theta 0 p \theta \alpha \mathrm{l}$ is clear enough, but $\tau \dot{\varepsilon} \tau o p \theta \alpha$ and $\mu \varepsilon^{\prime} \mu \rho p \theta \alpha \mathrm{l}$ are difficult to interpret etymologically. Now, $\stackrel{\varepsilon}{\varphi} \theta 0 p \theta \alpha \iota$ may have an analogical vowel slot ( $\varphi \theta \varepsilon \rho-, \varphi \theta 0 \rho-, \varphi \theta \alpha \rho-)$ and does not speak against a regular develop-

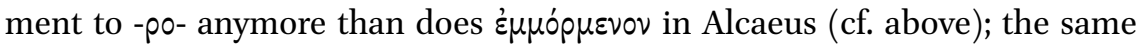
may be true of $\tau \dot{\varepsilon} \tau o p \theta \alpha l$ and $\mu \varepsilon \dot{\varepsilon} \mu \rho \rho \alpha l$, whatever their etymology is.

Having said that, one pair of glosses attested in Hesychius clearly supports the Aeolic development of $o$-vocalism that we have just established on the basis of the literary and epigraphic evidence: $\pi \circ p v \alpha \dot{\alpha} \mu \varepsilon v \cdot \pi \omega \lambda \varepsilon i \hat{i}^{\prime}$ to sell' and $\pi \circ p \nu \alpha \dot{\mu} \mu v \alpha l \cdot$

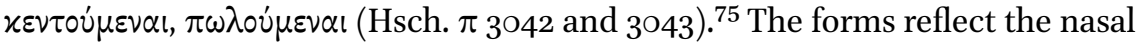
present-stem " $p r-n-h_{2}$ - that is also continued as Ionic $\pi \dot{\varepsilon} p \nu \eta \mu$ ' 'to sell', with the difference that in the latter form, the root vowel was secondarily adapted to that of the aorist $\pi \varepsilon \rho \dot{\alpha} \sigma \alpha{ }^{76}{ }^{7 n} \pi$ In $\pi v \alpha \dot{\alpha} \varepsilon v$, the $o$-vocalism in combination with the infinitive ending $-\mu \varepsilon v$ clearly suggests an Aeolic origin. The vowel slot -opcould be conditioned by the following nasal, or be analogical after the aorist $\pi \varepsilon p \dot{\alpha} \sigma \alpha .{ }^{77}$

\subsubsection{Conclusions on Aeolic}

The forms $\sigma \tau p o ́ \tau o \varsigma ~ ' a r m y '$ and $\alpha \mu \beta p o \tau \eta \nu$ 'to err' provide clear evidence for the development of an anaptyctic vowel -o- after the liquid in Aeolic dialects. This

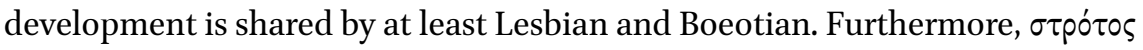

73 For instance, the $o$-grade root could be original, or an onset /ptro-/ (with the expected Aeolic reflex) may have been avoided.

74 These forms are adduced in the context of a discussion of the accentuation of the Homeric

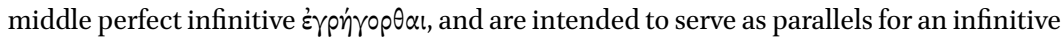
ending in -op $\theta \alpha$ l with proparoxytone accent (instead of the expected paroxytone). Accord-

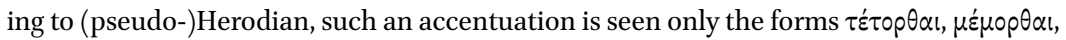
$\ddot{\varepsilon} \varphi \theta 0 p \theta \alpha \iota$ in Aeolic ( $\tau \hat{\eta}$ Aì $\lambda(\hat{\delta} \iota)$.

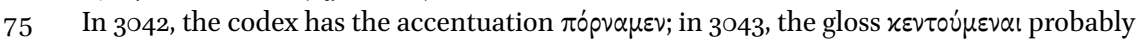
belongs elsewhere.

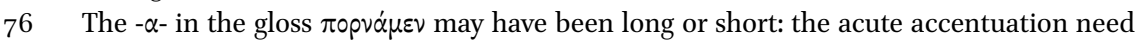
not be original.

For further discussion, see section 9.4. 
proves that the $o$-coloring was not conditioned by a neighboring labial sound. The Thessalian evidence is somewhat less straightforward, but all attested forms are compatible with the development established for Boeotian and Lesbian: $\Theta p \circ \sigma i \alpha$ and $\pi \varepsilon \tau \rho \circ \tau \circ \varsigma$ render this likely. We may therefore reconstruct ${ }^{*} r>$ -po-for Proto-Aeolic.

It is important to state this conclusion in clear terms, especially given the discussion of the reflexes of ${ }^{*} r$ in the Aeolic dialects by Parker (2008: 446-447). Parker's general tenet is that the Aeolic dialects have no shared innovations: he describes most of the typical Aeolic features as choices made independently by Boeotian, Lesbian and/or Thessalian. However, García Ramón (2009) has shown convincingly that Parker's arguments are misguided. Not only are there at least two shared innovations between Lesbian and Thessalian, but the three dialects in fact share a bundle of features (often non-trivial choices between alternatives) that cannot be due to language contact at a recent stage, as the dialect regions are geographically non-contiguous.

Now, the development ${ }^{*} r>-p o$ - is perhaps the most salient of all common phonological innovations of the Aeolic dialects, especially now that it has been shown that the vowel /o/ regularly follows the liquid only here, not in Mycenaean (cf. chapter 2) or in Arcadian (section 3.4). When Parker states that " ${ }^{\prime *} r$ $>p o / p \alpha$ is a comparatively late change in various Greek dialects" (2008: 447), I agree that * $r$ may well have been retained until the late (or sub-)Mycenaean period in many dialects, including Ionic-Attic (cf. chapters 6 till 9) and West Greek (sections 3.1 and 3.2). However, this does not imply that the change is "not very important for grouping Greek dialects", as Parker states with a misleading reference to Cowgill. Apart from Boeotian, Lesbian and probably Thessalian, there is no other dialect for which we know for certain that the reflex of ${ }^{*} r$ was -po-. Moreover, it is uncommon in other IE languages for the anaptyctic vowel to develop after the liquid: the only clear example of such a treatment is Celtic, where ${ }^{*} \mathrm{Cr} T$ - developed to ${ }^{*}$ CriT- (cf. OIr. cride 'heart' < * $k_{0}$ dido-). Given that Thessalian, Boeotian and Lesbian are not geographically contiguous, the only logical conclusion is that the isogloss ${ }^{*} r>-p o$ - is an innovation of their common ancestor, which we may call Proto-Aeolic. ${ }^{78}$

78 According to García Ramón (1975:63), who starts from the position that * $r$ was still intact in Mycenaean, "la conclusion s'impose d' elle-même: le proto-thessalien a développé * $r$ > $o \rho, p o$ à une époque où les Béotiens ne s'étaient pas encore séparés de la Thessalie, mais postérieure en tout cas à ca. 1200." Note, however, that the regular vowel slot was not a relevant issue for García Ramón. For a discussion of further phonological and morphological arguments in favor of positing a Proto-Aeolic stage, see García Ramón (1975: 6o-68) and (2009: 232-234). 
It is difficult, however, to determine the date of this Proto-Aeolic vocalization to -po- more precisely. In my view, it is likely that the change took place before the end of the Mycenaean period: this allows us to understand why the Aeolic dialects did not develop an $a$-colored reflex, as Ionic-Attic and neighboring West Greek dialects did. Another important common Aeolic innovation, the generalization of $-\varepsilon \sigma \sigma$ las a general 3 rd declension dative plural ending (except in the $s$-stems), may also have taken place in the Mycenaean period, as I hope to show elsewhere.

\subsection{Arcado-Cyprian}

Fraenkel (1911: 250-251) was one of the first scholars to explicitly state that the $o$-colored outcome is regular in Arcado-Cyprian. He adduced the forms $\pi \alpha \nu \alpha-$

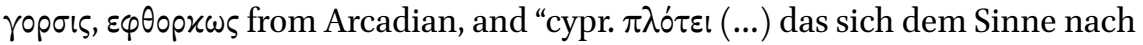
mit sonstigem $\pi \lambda \dot{\alpha} \tau \varepsilon$ ı deckt”. This thesis was quickly taken up by the handbooks, and it remained the standard view until Morpurgo Davies proposed that the instances of $o$-coloring were conditioned by a preceding $u$-. In her words, "both in Arcadian and Cyprian the reliable instances of $a R / R a$ considerably outweigh those of $o R / R o$. This amounts to saying that the data definitely favour the suggestion that $a R / R a$ and not $o R / R o$ is the regular treatment of $R$ in these dialects" (1968: 808).

Since then, scholars have occasionally doubted that $o$-vocalism was the only regular outcome in Arcadian and/or Cyprian. For instance, Egetmeyer (2010: 144) remarks that the Cyprian outcome is uncertain because of a lack of clear examples. However, much of the alleged evidence for $a$-vocalism in both dialects was adduced for incorrect reasons, notably in Morpurgo Davies (1968). In my view, scholars like García Ramón (1985) and Haug (2002: 49-67) are right to insist that only the $o$-colored outcome is regular in Arcadian and Cyprian. Nevertheless, whether the two dialects underwent a common development of * $r$ remains, in my opinion, an open question.

The evidence below has been collected from Morpurgo Davies (1968), Haug (2002) and the dialectal grammar by Egetmeyer (2010: 144-147).

\subsubsection{Cyprian: Evidence for o-vocalism}

There are five more or less reliable forms with $o$-vocalism in Cyprian, three of which are attested in glosses ascribed by Hesychius to the dialect of Paphos

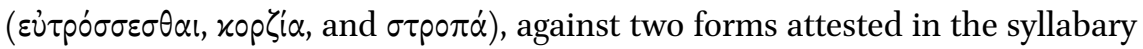
(ka-te-wo-ro-ko-ne, to-ro-su-ta-mo-se). Another form that was previously adduced ( $\theta \dot{\rho} \rho v \alpha \xi \cdot$ i $\pi \circ \pi \delta ́ \delta 10 v$ Hsch.) has no bearing on the discussion. 
- ka-te-wo-ro-ko-ne /kat-ěworgon/ or /kat-ěwrogon/79 'they besieged' (ICS ${ }^{2}$ 217.1, Egetmeyer 2010: 481) is a zero grade thematic 3 rd pl. from the root of

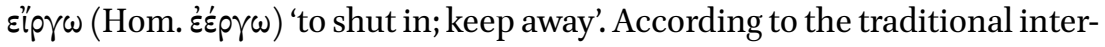
pretation, this form is an aorist (cf. GEW s.v. Elp $(\omega)$ ). ${ }^{80}$ Morpurgo Davies (1968) doubted whether the form reflected a zero grade root with the argument that there is no independent evidence for a thematic aorist from this verb, and she followed a suggestion by Schwyzer (1939: 777) to compare it with $\alpha^{\prime} v \omega \gamma$ ov, a thematic pluperfect found in the next line of this inscription (a-no-ko-ne 'they ordered' ICS 217.2 ). However, since $\alpha \omega \omega \gamma$ ov is clearly an exceptional case and is also attested in Homer, the interpretation of ka-te-wo-ro-ko-ne as a thematic aorist or imperfect must be preferred. Thus, the form serves as reliable evidence for an $o$-colored reflex.

- A PN to-ro-su-ta-mo, either $/ \mathrm{T}^{\mathrm{h}}$ rosu-dāmō/ or $/ \mathrm{T}^{\mathrm{h}}$ orsu-dāmōol, occurs in an inscription from Paphos that was dated to $75^{\circ}-600$ BCE (cf. Neumann 2004: ${ }^{138}-139$ for the reading). The antiquity of the inscription suggests that we are dealing with a genuine reflex of ${ }^{*} r$ in Cyprian. Egetmeyer (2010: 146) argues that $/ \mathrm{T}^{\mathrm{h}}$ rosu-/ is the correct interpretation of the first member, but as Neumann (l.c.) remarks, there is no way to exclude $/ \mathrm{T}^{\mathrm{h}}$ orsu- $/$.

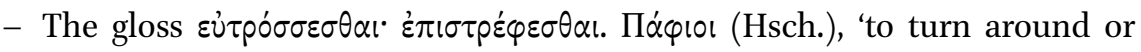
towards', is mostly thought to derive from a yod-present ${ }^{*}-t_{o} k{ }^{w}-i e / o-{ }^{81} \mathrm{Al}-$ though scholarly opinion is still divided concerning the assumed equivalence of Cypr. $\varepsilon \dot{\text { - }}$ (as a preverb) and Ion.-Att. $\dot{\varepsilon} \pi-{ }_{-},{ }^{82}$ the most widely accepted

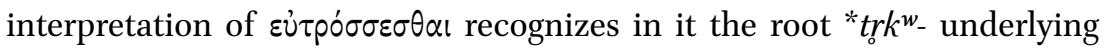

79 On the basis of the syllabary, all four interpretations are possible, though a long vowel (an augmented form of the root *euerg-) is in my view more likely.

8o Tichy (1983: 287 n. 165) views ka-te-wo-ro-ko-ne as the imperfect of a root PGr. *uerg- 'to shut in, lock up', which she distinguishes (1983: 286-288) from PGr. *euerg- 'to shut out,

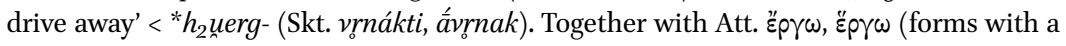
short root vowel) and the Avestan opt. varaziian 'to fence in', she derives the Cypriot form from an ablauting athematic root present. Whether this is correct or not is not directly relevant for present purposes, because ka-te-wo-ro-ko-ne would have a zero grade root also in Tichy's interpretation.

81 See e.g. Egetmeyer (2010: 146).

82 For extensive discussion and further literature on Cypr. $\varepsilon \dot{u}-, u$-, cf. Egetmeyer (2010: 450452). The best piece of evidence for * $u d$ - as a relic alternative form of $\dot{\varepsilon} \pi-$ is $u$-ke-ro-ne (ICS 217.A 5, 15), interpreted as a gen. pl. /u-khērōn/ lit. "what is on the hand", i.e. 'supple-

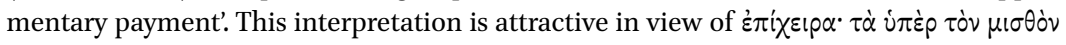

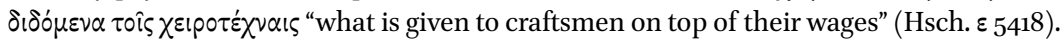
It remains unclear to me, however, how $u-<{ }^{*} u d$ - would relate to $\varepsilon \dot{v}$ - in the glossed form

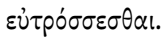


$\tau p \varepsilon ́ \pi \omega{ }^{83}$ Morpurgo Davies (1968: 80o) claimed that "in the absence of any other evidence a denominative formation on an -o-grade substantive cannot be excluded", but this seems highly unlikely: in all other Greek dialects, denominatives from $o$-grade thematic nouns are in $-\varepsilon \omega .{ }^{84}$ The most plausible reconstruction remains ${ }^{*}$-tro $k^{w}-i e / o-$, even if some doubts persist concerning

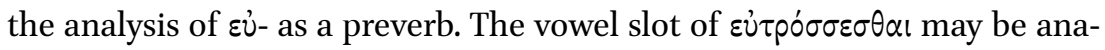
logical, cf. $\tau \rho \dot{\varepsilon} \pi \omega$.

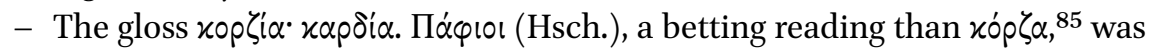
disqualified by Morpurgo Davies (1968: 8o1, 812) with the remark "but this is a gloss attested only in Hesychius". If the other available evidence spoke against $o$-vocalism, this would perhaps be a legitimate way of arguing, but since there is no compelling evidence for $a$-vocalism in Cyprian (see below), it is best to take the gloss seriously, especially given its remarkable $\langle\zeta\rangle$.

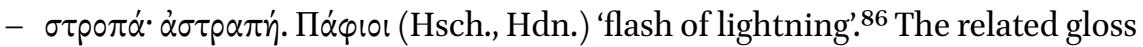
$\sigma \tau 0 \rho \pi \dot{\alpha} v \cdot \tau \dot{\eta} \nu \dot{\alpha} \sigma \tau \rho \alpha \pi \dot{\eta} \nu$ (Hdn., Hsch., without dialect indication) might well be Arcadian in view of $\Delta \cos \Sigma \tau 0 \rho \pi \alpha 0$ in an Arcadian inscription (gen.sg., IG $\mathrm{v}, 264,5$ th c.). The aspirated stop in the gloss $\sigma \tau p \circ \varphi \alpha i \cdot \dot{\alpha} \sigma \tau \rho \alpha \pi \alpha i$ (Hdn., Hsch.) might be folk-etymological after $\sigma \tau \rho \varepsilon ́ \varphi \omega$. As for the real etymology, Beekes (1987) has convincingly criticized the reconstruction ${ }^{*} h_{2} s t r-h_{3} k^{w_{-}}$"star-eye", which is not evident semantically and, even worse, does not explain the forms without prothetic vowel or the lacking reflex of ${ }^{*} h_{3}{ }^{87}$ Still, since forms with $o$-vocalism appear precisely in Arcadian and Cyprian, a reconstruction with syllabic liquid might be considered. One would then have to reconstruct a Proto-Greek root *strp- $\bar{a}$, of unknown etymology, with a variant *astrp- $\bar{a}$ continued in the Classical form $\dot{\alpha} \sigma \tau p \alpha \pi \dot{\eta}$ and in the epic denominative verb $\dot{\alpha} \sigma \tau \rho \dot{\alpha} \pi \tau \omega$. In this case, the reflex - $\rho \alpha$ - in the Classical Attic form would be difficult to rhyme with the claims made in this book. However, the

83 “* ${ }^{\prime} k^{w}{ }^{w}-i e ́ / o ́-. .$. reste l'hypothèse la plus solide" (Egetmeyer 2010: 464). See there for other, less likely proposals.

84 Cf. Myc. to-ro-qe-jo-me-no / trok ${ }^{\mathrm{w}} \mathrm{e}(\mathrm{i})$ omeno-/ 'making tours of inspection'.

85 As it is usually cited, the form $\varkappa$ ó $\rho$ ‘ $\alpha$ would presuppose a desyllabification of $-i$ - and the subsequent development of *-di- to $\langle\zeta\rangle$ in Cyprian. However, as Egetmeyer (2010: 125126 , with discussion of earlier literature) remarks in his discussion of the gloss, the codex

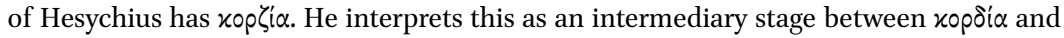

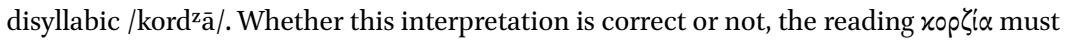
be maintained.

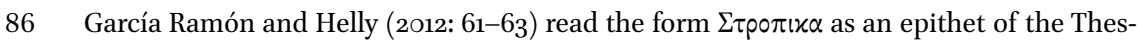
salian goddess Ennodia in a dedication from Larisa $(S E G 54,561$; 3 rd quarter of the 5 th c.). If this is correct, the variant $\sigma \tau \rho \circ \pi \dot{\alpha}$ is also secured for Thessaly.

87 The last point is not addressed by Peters (1980: $208 \mathrm{fn}$. 160), who thinks that the absent reflex of the initial ${ }^{*} h_{2}$ - can be due to laryngeal loss in a compound. 
word may well be of non-Indo-European etymology: the variation between forms with and without prothetic $\dot{\alpha}$-, and the difference in vocalism between Homeric $\sigma \tau \varepsilon \rho \circ \pi \eta$ ', $\alpha \sigma \tau \varepsilon \rho \circ \pi \eta$ ' and $\dot{\alpha} \sigma \tau \rho \alpha \pi \dot{\eta}$ (with 'reduced' vocalism) are both typical substrate phenomena (Beekes l.c.; Schrijver 20o1: 419). Furthermore, it cannot be excluded that contaminations took place between two or more different pre-forms. In view of this, no conclusions can be based on these forms. ${ }^{88}$

- The gloss $\theta \dot{\rho} p v \alpha \xi$ i $\pi 0 \pi \delta ́ \delta 10 v$ 'footstool' (Hsch. $\theta 647$ Latte) at one point received the addition Kúmplor (thus e.g. $G E W$ ), but Latte no longer prints this because he thinks the ethnicon was wrongly taken over from the preceding gloss (cf. Egetmeyer 2010: 147). The word is clearly derived from Myc. to-no $/ \mathrm{t}^{\mathrm{h}}$ ornos/, alph. Өpóvos, but its pre-form may not have contained * $r$ at all (see chapter 7$) .89$

\subsubsection{Cyprian: Evidence for a-vocalism}

Morpurgo Davies (1968: 799-801) and Egetmeyer (2010: 145) list several pieces of evidence for $a$-vocalism, but none of them is compelling.

First of all, as explained in section 1.2, we must leave aside all forms where * $r$ may have been vocalized as part of a Common Greek development, e.g.:

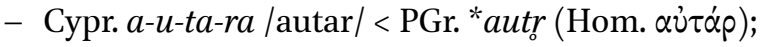

- Cypr. ka-i-re-te / $\mathrm{k}^{\mathrm{h}}$ airete/ < PGr. ${ }^{*} k^{h}$ arie $/ o$ - < PIE ${ }^{*} \dot{g}^{\prime} h_{0}$-ie/o-

Forms for which there is no clear reason to reconstruct a syllabic liquid can also be disregarded:

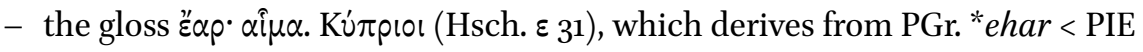
${ }^{*} h_{1} e s h_{2} r$ (cf. Hitt. ēshar 'blood');

- the verb $\mu \alpha \dot{\alpha} \rho \tau \omega$ (Morpurgo Davies 1968: 801) appears in the $\gamma \lambda \omega \sigma \sigma \alpha l ~ \varkappa \alpha \tau \dot{\alpha}$

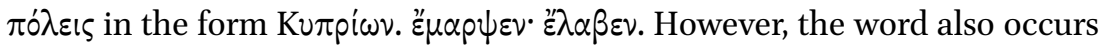
in both epic and Lesbian lyric, and has no clear etymology (see section 9.7.2). Some of the Cyprian forms with - ar-, -ra- look like imports from Ionic-Attic:

- Personal names in -xpátns are also attested in Ionic-Attic and appear only late in Cyprian; they must therefore be borrowings (see Egetmeyer 2010:327330 and already Morpurgo Davies 1968: 80o);

88 Thus also Haug (2002: 6o). Note that the interpretation of Myc. to-pa-po-ro-i as /storpāp $^{\mathrm{h}}$ oroihi/ 'for the torch-bearers' (thus e.g. Waanders 2008: 37, Egetmeyer 2010: 146) is uncertain; for an alternative interpretation /torpā-p ${ }^{\mathrm{h}}$ oro-/, connecting Att. $\tau \dot{\alpha} \rho \pi \eta$ denoting a type of basket, see chapter 2 .

89 Compare the skepticism of Egetmeyer (2010: 147) on this gloss; I disagree with him, however, on the inclusion of Өpóva 'varicolored embroideries' among the Cyprian evidence for ${ }^{*} r$ (on this word, see section 2.5.2). 


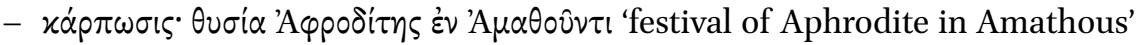
(Hsch.) is derived from the problematic word xap $\pi$ ś, which has this very shape in all Greek dialects where it is attested.

- The form $\tau \alpha \rho \beta \varepsilon \hat{\imath}$ is ascribed to Cyprian by the $\gamma \lambda \hat{\omega} \sigma \sigma \alpha l$ к $\alpha \tau \dot{\alpha} \pi \dot{\lambda} \lambda \varepsilon ı \varsigma$ (cf. Ruijgh 1957: 163). However, in spite of Bowra (1959), this list of dialectal words is in my view not fully trustworthy as a source for the spoken dialects of Ancient Greek. ${ }^{90}$ The verb $\tau \alpha \rho \beta \varepsilon^{\prime} \omega$ is frequent in Homer, but also in the tragedians; it is therefore not excluded that the word is of Ionic-Attic origin. The reconstruc-

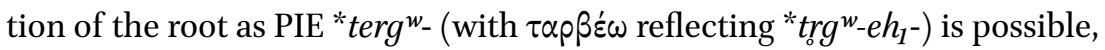
but not compelling. ${ }^{91}$

There are two Cyprian forms containing a sequence $\langle\mathrm{Ca}-\mathrm{ra}\rangle$ for which a preform with syllabic nasal may be reconstructed:

- As I will argue in section 9.1.4, the imperative ka-ra-si-ti /grast ${ }^{\mathrm{h}}$ / 'eat!' can be the regular outcome of a pre-form * ${ }^{*} r_{0} s-d^{h} i$.

- The form ta-ra-ka-ma-ta/dragmata/ 'sheaves; first fruits' (ICS $318 \mathrm{~A} \mathrm{III,}$

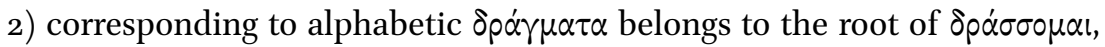
which did not have ablaut and whose - $\alpha$ - may reflect a vocalized nasal (see section 9.2.1).

\subsubsection{Arcadian: Evidence for o-vocalism}

The epigraphic evidence unambiguously proves that Arcadian had an $o$-colored regular reflex, independent of the preceding consonant. This was already argued clearly by Haug (2002: 60); moreover, two forms that were recently discovered in an archaic Arcadian festival calendar (editio princeps: CarbonClackson 2016) must be added to the dossier. ${ }^{92}$ The forms are discussed in alphabetical order.

- Arc. Bpoxv[ (Dubois 1988: 43 with n. 212). Morpurgo Davies doubts the Arcadian origin of the form. Dubois could not find the stone in the museum of Dimitsana, but as he remarks (ibid., n. 212, cf. also Haug 2002: 6o), "il est peu probable qu' il y ait eu dans ce musée beaucoup de pierres errantes éoliennes." The place of the vowel in $\beta p o x v$ can be analogical after the full grade in the forms of comparison, like that of Class. $\beta$ paxús (cf. section 4.3.3).

90 Leumann (1950: 273) thinks that the ascription Kv $\pi$ pi $\omega v$ of glosses (e.g. those in the $x \alpha \tau \dot{\alpha}$ $\pi \dot{o} \lambda \varepsilon ı \varsigma$ list) may conceal the fact that these words occurred in the epic poem with the title Cypria. Although some of Leumann's views are in my view far-fetched, a skeptical attitude towards the glosses marked as 'Cyprian' seems in order.

$91 \quad$ For further discussion of $\tau \alpha \rho \beta \varepsilon$ '́ $\omega$ and cognates, see section 4.2.1.

92 Unfortunately, the more precise provenance of this text within Arcadia is unknown. 
- According to Morpurgo Davies (1968), following Chantraine and Wackernagel, the Arc. form $\varepsilon \varphi \theta 0 p x \omega \varsigma$ (IG v,2 6.10-11 = Del. $\left.{ }^{3} 656\right)$ may have been influenced by the older root perfect (Att. $\delta$ - $-\dot{\varepsilon} \varphi \theta 0 \rho \alpha$ ). However, as Haug (2002: $60)$ remarks, the classical $x$-perfect was normally derived from a middle perfect (cf. Attic $\ddot{\varepsilon} \varphi \theta \alpha p x \alpha$ from $\tilde{e}^{\prime} \varphi \theta \alpha \rho \mu \alpha$ ). Moreover, in Ionic-Attic one never finds intrusion of the $o$-vowel from the active into the middle perfect. Therefore, I agree with Haug and with Dubois (1988: 44) that $\varepsilon \varphi \theta 0 p x \omega \varsigma$ probably implies the existence of an Arcadian middle perfect ${ }^{*} \varepsilon \varphi \theta 0 p \mu \alpha$, with an $o$ colored reflex of ${ }^{*} r$.

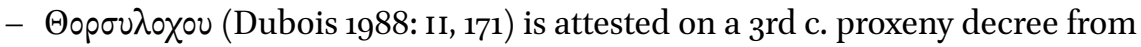
Orchomenos. Morpurgo Davies (1968: 794) remarks that the name refers to a person from Achaea and excludes the form as evidence. Haug (2002: 6o) prefers to see in $\Theta \circ \rho \sigma v-$ the regular development of a zero grade, and Dubois (ad loc.) follows Masson (1972) in seeing in this form an element of the pre-Doric substrate in Achaea. Note, in this context, the Cyprian man's

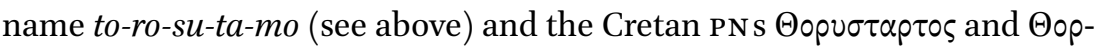
ous (Masson 1972, Leukart 1994: 191). It is hard to base any conclusions on this form, because it is a name.

- Arc. $\pi \alpha v a \gamma o p \sigma \varsigma \varsigma$ name of a festival, lit. "all-gathering" $\left(I G \mathrm{v}, 23.26=D e l .{ }^{3} 654\right)$, also in the month name $\pi \alpha v \alpha \gamma o p \sigma i o v$ (ibid. 3.3), $\tau$ pi $\pi \alpha v \alpha \gamma o p \sigma i o s$ (ibid. 3.7). The word is now also attested in its expected dialectal form $\pi \alpha v a \gamma o p l$ (CarbonClackson 2016) with simple spelling of the geminate resulting from the

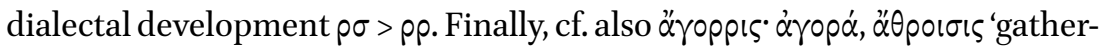
ing' (Hsch., without dialect identification). A zero grade reflex is also attested in the form arappls 'meeting' (IG XIV, 659, lines 12 and 16) found in a Western Ionic colony. ${ }^{93}$ As a comparison between Arcadian and Western Ionic confirms, the original form was *agr-ti-. ${ }^{94}$ As Dubois remarks, Eastern Ionic

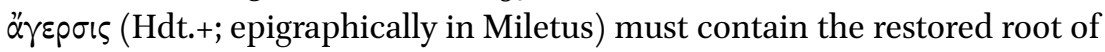
$\alpha \gamma \varepsilon i \rho \omega$, while Arcadian $\pi \alpha v \alpha \gamma o p \sigma \iota \varsigma / \pi \alpha \nu \alpha \gamma o \rho(\rho) \iota \varsigma$ and Western Ionic $\alpha \gamma \alpha p p \iota \varsigma$ show the etymologically expected zero grade root.

The form arappis was discarded as "doubtful evidence" by Morpurgo Davies (1968: 794), for the reason that it occurs in a "late inscription, in which the only other dialect formations are $\varphi p \eta \tau p i \alpha$ and its derivatives". In her view, it

In Van Beek 2013 I suggested that the Mycenaean month name a-ma-ko-to me-no /hamagortō mē(n)nos/ "in the month of the assembly" (cf. Taillardat 1984) reflects PGr. *smplus *agr-to-. However, the underlying form could also be an $o$-grade formation PGr. *ágor-

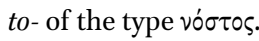

94 Of course, the vowel slot of $\alpha$ rappı could theoretically be analogical after the full grade of the verbal root. For the vocalization of ${ }^{*}-r s^{-}$, see section 9.1. 
is "quite possible" that arappıৎ arose by vowel assimilation from $\alpha$ ' $\varepsilon p p ı$, but this is clearly an ad hoc assumption. ${ }^{95}$ The fact that both $\alpha \gamma \alpha p p ı$ and $\varphi p \eta \tau p ı \alpha$ seem to denote institutions peculiar to this colony suggests that the form ayappıs preserves older morphology. Moreover, as Dubois (1995: 86) remarks, arappis shows the expected result of - $\rho \sigma$ - in Western Ionic and cannot therefore be a Koine form. Finally, as Haug (2002: 60) remarks, an $o$-grade root is excluded in an abstract noun in - $\sigma \varsigma$.

- The Arcadian form of the word for 'male' (with $\rho \rho<\rho \sigma$ ) has been known for

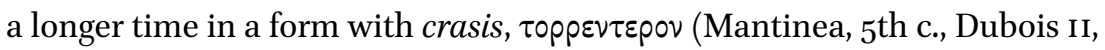
$94 \mathrm{ff}$. and 105). It remained unknown, however, whether this form had

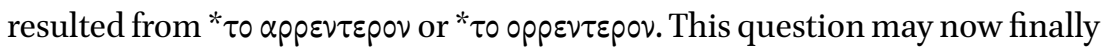
be resolved after the appearance of opev, with single spelling of the geminate, on a newly published festival calendar (Carbon-Clackson 2016). The form $\alpha$ p $\varepsilon v \alpha$ (Tegea, 4 th c.) must be a Koine form: see below.

- As for Arc. $\Sigma \tau 0 \rho \pi \alpha 0$, epithet of Zeus, see the discussion of the Cyprian gloss $\sigma \tau p o \pi \alpha \dot{\alpha}$ above. It remains uncertain whether the pre-form contained ${ }^{*} r$.

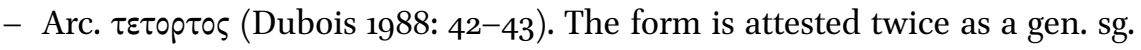
$\tau \varepsilon \tau o p \tau \alpha v$ and probably once in a broken attestation as a nom. $\tau \varepsilon \tau] \circ \rho \tau \alpha$. As a

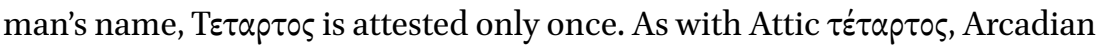
$\tau \varepsilon \tau о \rho \tau о \varsigma$ cannot be explained by analogy, because the cardinal form is $\tau \varepsilon \sigma \sigma \varepsilon-$ pes. ${ }^{96}$ I cannot accept the reasoning of Morpurgo Davies (1968: 795) that the

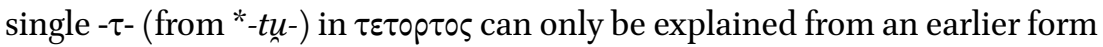

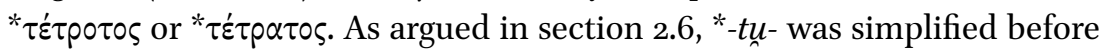
${ }^{*} r$ in this word prior to the vocalization of the syllabic liquid.

\subsubsection{Arcadian: Evidence for a-vocalism}

As Haug (2002: 59-61) makes clear, the counterevidence to a regular vocalization ${ }^{*} r>-o p$ - in Arcadian merely consists of the forms $\delta \alpha \rho \chi \mu \alpha, \gamma \rho \alpha \varphi \omega$ and $\sigma \tau \rho \alpha \tau \alpha \gamma \circ \varsigma$. There are two possible ways to explain these forms: either they are non-dialectal words, or they have - $\alpha p$ - or $-\rho \alpha$ - for some other reason.

- As was already remarked e.g. by Ruijgh (apud Morpurgo Davies 1968: 813), $\sigma \tau p \alpha \tau \alpha \gamma \circ \varsigma$ could well be a borrowing from Doric. He compares the military term Att. $\lambda \circ \chi \alpha \gamma o ́ s$, where the long $-\bar{\alpha}$ - excludes a native Ionic-Attic word, and which is generally accepted to be a Doric borrowing.

95 See Van Beek (2011a) for a criticism of "vowel assimilations" in Greek, and cf. also the doubts expressed by Dubois (1988: 44 with n. 219).

96 Note, in this connection, that $\tau \varepsilon \tau o ́ p \tau \alpha \operatorname{los}$ (Theoc. 30.2) is inadmissible as evidence for a Lesbian form $\tau \dot{\varepsilon} \tau о р \tau о \varsigma^{*}$. The form in Theocritus (of unknown dialectal origin) may be analogical and based on the Doric cardinal $\tau \dot{\tau} \tau o p \varepsilon \varsigma$. 
- The root of $\gamma p \alpha \dot{\varphi} \varphi \omega$ has $a$-vocalism in all Greek dialects, except in the agent noun Ypoprús 'scribe' attested in various dialects, mainly on the Peloponnese (see section 9.2.2 for a discussion of the details). Arcadian has $\gamma \rho \alpha \varphi \varepsilon \alpha$

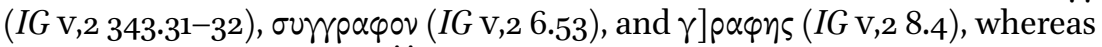

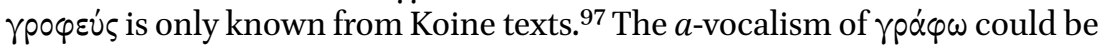
the reflex of a vocalized nasal (section 9.2.2).

- It is hard to utilize $\delta \alpha \rho \chi \mu \alpha$ as evidence: as a word designating a monetary unit, it may have easily been borrowed from another dialect. Indeed, the same form is found in the neighboring West Greek dialect of Elis, as well as on Crete. Moreover, the Boeotian dialect of Thespiae also offers instances of $\delta \alpha p \chi \mu \alpha \alpha$ (Roesch, IThesp. 38 and 39), which cannot have the genuine reflex of ${ }^{*} r$ in Aeolic, as we have seen above. ${ }^{98}$

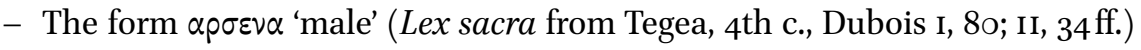
cannot be used as evidence, because the genuine Arcadian form with -pp-

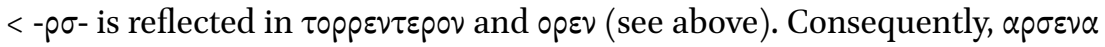
must be a literary or Koine form. ${ }^{99}$

\subsubsection{Conclusions on Arcado-Cyprian and Achaean}

As Haug (2002) has convincingly shown, Morpurgo Davies was mistaken in positing a regular vocalization ${ }^{*} r>-\alpha \rho-,-\rho \alpha-$ for Arcadian. The forms $\pi \alpha v \alpha \gamma o p-$

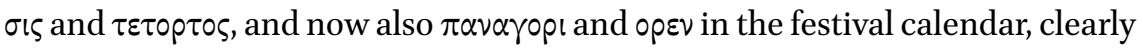
show that the $o$-colored reflex was regular in this dialect also in non-labial environments. The $o$-vowel of $\varepsilon \varphi \theta 0 p x \omega \varsigma$ further supports for this conclusion. The situation in Cyprian is a bit less clear, but here too, the gloss xop $\zeta i \alpha$ and the ver-

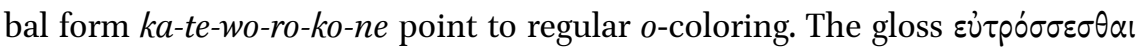
and the PN to-ro-su-ta-mo support this conclusion.

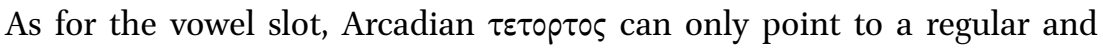
unconditioned vocalization to -op-. The same outcome is found in $\pi$ avarop-

97 According to Minon (2007: 301-302), the Elean alphabet was taken over from the Laconians. This would explain why ypopev́s is found in that dialect. Is a similar explanation

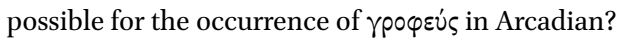

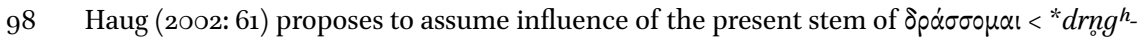
on $\delta \alpha p \chi \mu \alpha$ in Arcadian and Aeolic, but this does not explain the deviating vowel slot in comparison with Class. $\delta \rho \alpha \chi \mu$. One might therefore think that $\delta \rho \alpha \chi \mu \eta$ underwent the influence of the present stem, while $\delta \alpha p \chi \mu \alpha, \delta \alpha p X \nu \alpha$ contain the regular outcome of PGr. *drk $k^{h} m n \bar{a}$. See section 9.2.1.

99 Pace Morpurgo Davies (1968: 796), whose speculations on geographically different treatment of -rs- are not supported by the evidence; cf. Dubois (1988: 8o-83), who argues that - $\rho p$ - is found until the late $5^{\text {th }} \mathrm{c}$., and that it later developed (from the 4 th c. onwards) into a form with compensatory lengthening. 


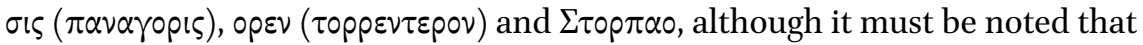
$\Sigma \tau o p \pi \alpha o$ has no clear etymology, that opev is a unique example for ${ }^{*}{ }^{r}$ - in wordinitial position, and that the vowel slot in $\pi \alpha v \alpha \gamma o p(\sigma) \iota \varsigma$ may have been influenced by that of the full grade form. In order to determine the regular vowel slot in Cyprian, we have to rely on glosses in view of the nature of the Cyprian

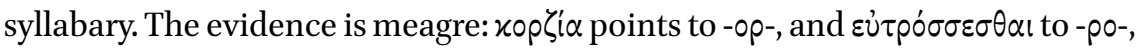
but the latter form might be analogical.

Although the evidence is less extensive, the situation in Arcado-Cyprian is similar to that in Mycenaean. There is no clear evidence for an $a$-colored outcome, and there is some reliable evidence for $o$-vocalism. ${ }^{100}$ In view of these similarities, one could be tempted to reconstruct a Proto-Achaean vocalization ${ }^{*} r>$ > or- (the Arcadian reflex was clearly -op-), but we have to be careful. While a vocalization to -ro- can be excluded for Mycenaean, this dialect may have preserved ${ }^{*} r$ (chapter 2), and the forms tu-ka-ta-și and a-na-qo-ta perhaps support this (cf. section 2.4). Furthermore, a Cyprian outcome -ro- cannot be completely excluded on the basis of our evidence. It thus remains unclear whether Mycenaean and Cyprian had an outcome -or- in the first place.

If Mycenaean did preserve ${ }^{*} r$, the Arcadian reflex -op- may have come into being in the sub-Mycenaean period, before speakers of West Greek dialects established themselves on the rest of the Peloponnese. The Cyprian reflex (if it was indeed -or-) may then be an isogloss with Arcadian, but since a development to -or- is phonetically more natural than a development to -ro-, an independent vocalization in both dialects is difficult to exclude.

\subsection{Pamphylian}

The view that Pamphylian, like Cretan, could undergo liquid metathesis has been codified in Brixhe's grammar (1976: 61-63). He adduces five items as evidence:

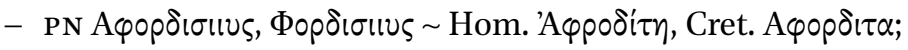

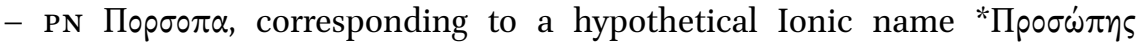
'Face';101

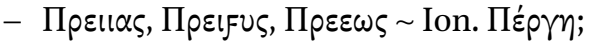

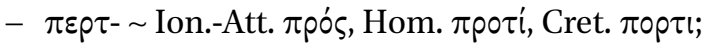

100 The regular outcome of * $!$ is unclear in all three dialects.

101 Brixhe's comment, "qui sans doute est une forme partiellement extra-dialectale pour "Пробó $\pi \alpha$ " (1976: 61), is difficult to understand. Does he mean that the liquid metathesis points to extra-dialectal origin? 
- $\Sigma \tau \lambda \varepsilon \gamma u u \varsigma, E \sigma \tau \lambda \varepsilon \gamma u \cup \varsigma$, supposed to derive from a pre-form *sleg- with $t$-epenthesis non-Pamph. $\Sigma \dot{\varepsilon} \lambda \eta \eta^{102}$

In Brixhe's view, these five forms show that liquid metathesis may work in both directions, and that the phenomenon affected not only the outcome of * $r$ or ${ }^{*}$ l, but also other sequences consisting of a vowel and liquid.

Upon closer consideration, however, these claims appear to be unfounded.

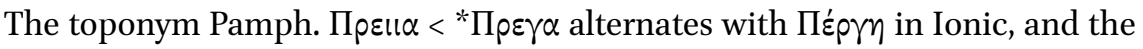
ethnic designation $\Sigma \tau \lambda \varepsilon \gamma$ $u \varsigma$ denotes an inhabitant of the town called $\Sigma \dot{\varepsilon} \lambda \gamma \eta$ in Ionic. Rather than proving metathesis, the alternations suggest that the Anatolian place names contained syllabic liquids in the donor language, and that these sounds were vocalized in two different ways in the Greek dialects in Asia Minor. This scenario is confirmed by the reflexes of the self-designation of the Lycians, not cited by Brixhe in this context. The Lycian form trĩmili- probably represents /trmili-/, at least originally. ${ }^{103}$ The Ionic counterpart is Teppí $\lambda$ al (Hdt. 1.173, 7.92, a form also attested epigraphically in Pisidia), but Pamphylian

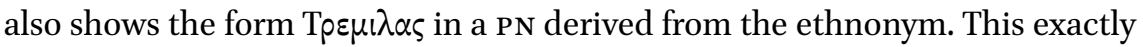

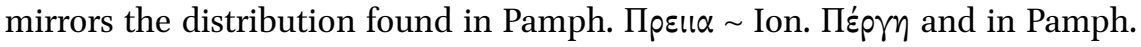
$\Sigma \tau \lambda \varepsilon \gamma u$ ${ }^{2} \sim$ Ion. $\Sigma \dot{\varepsilon} \lambda \gamma \eta$. Thus, certain sounds in names of Anatolian origin are reflected as - $\varepsilon \rho-,-\varepsilon \lambda$ - in Ionic, but as - $\rho \varepsilon-,-\lambda \varepsilon$ - in Pamphylian. Moreover, since an Anatolian pre-form with ${ }^{*} r$ is ascertained in Lycian trm̃mili-, we may hypothesize that the other toponyms were also borrowed from a language with syllabic $l$ and $r$. I propose the following scenario. ${ }^{104}$ When the borrowing into Pamphylian and Ionic took place, inherited PGr. * $l$ and ${ }^{*} r$ had already vocalized in these dialects. The sounds $!$ and $r$ from the donor language were initially rendered as [əl], [ər] in Ionic, but as [lə], [rə] in Pamphylian. Subsequently, the shwa in these renderings was identified as the phoneme spelled $\langle\varepsilon\rangle$ in both dialects. ${ }^{105}$

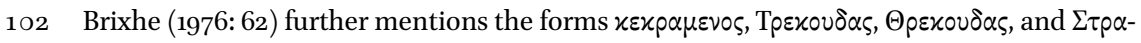

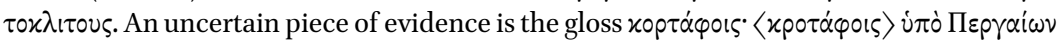

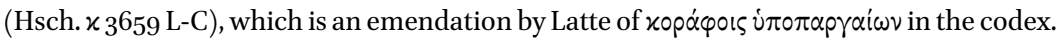

103 Melchert (2004: 595) thinks that an anaptyctic vowel had developed before syllabic nasals and liquids in attested Lycian spellings like hrppi [hərp.pi], as this would explain the use of a geminate spelling $-p p$ -

104 This scenario was proposed also in Van Beek 2013. Skelton (2017: 113), apparently without

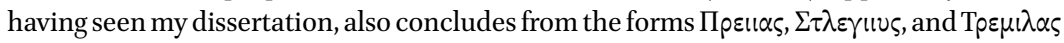
that they were taken from a Lycian-like Anatolian language with syllabic liquids. However, her claim that Pamphylian speakers still pronounced these syllabic liquids, and that $\rho \varepsilon$ is an attempt to render this in Greek alphabet, is clearly untenable: in this way one cannot explain the emergence of an epenthetic stop in $\Sigma \tau \lambda \varepsilon \gamma$ «us.

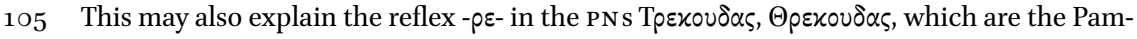
phylian reflexes of a borrowed Lyc. trqqñt- 'Storm God' (cf. Hitt. tarhunt-). 
Leaving aside these ethnonyms and toponyms, the potential evidence for inherited Greek ${ }^{*} r$ consists of the forms $\pi \varepsilon p \tau-$-, А we have seen in our discussion of the Cretan material, it is conceivable that both $\pi \circ \rho \tau \iota$ and A chapters 6 and 7 we will encounter metrical evidence that supports this claim. This means that the outcome of ${ }^{*} r$ in Pamphylian (at least after labials) was $-o p-.^{106}$ However, in this way the form $\pi \varepsilon \rho \tau$ - for $\pi \rho \circ \tau i$ would remain unexplained. Assuming liquid metathesis from PGr. "preti, as per Brixhe, has the disadvantage that an $e$-grade form of this preposition is not directly attested anywhere else in Greek. Bechtel (1921-1924, II: 820) proposed that $\pi \varepsilon \rho \tau \iota$ reflects *porti $<$ "prti in proclitic contexts, which deserves consideration. Wyatt (1978) suggested that $\pi \varepsilon \rho \tau \iota$ might be a cross between $\pi \varepsilon p i$ and $\pi \circ \tau i$.

In sum, there is not enough evidence to draw firm conclusions about the outcome of ${ }^{*} r$ or ${ }^{*} !$ in Pamphylian. If my scenario for the origin of Homeric muta

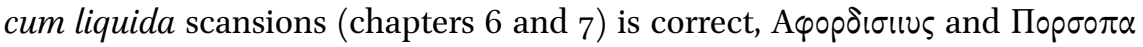
are suggestive of a development ${ }^{*} r>o p$ at least after labial consonants. However, the difference in vocalism between $\pi \varepsilon \rho \tau$ - and Порбo $\pi \alpha$ would still remain problematic (there is no compelling reason to assume that the former reflects *preti with liquid metathesis); in general, the inherited material is too scanty to allow for a definite conclusion. It is clear, on the other hand, that syllabic liquids in words borrowed from Lycian and related Anatolian languages are reflected as $-\rho \varepsilon$ - and $-\lambda \varepsilon$ - in Pamphylian.

\subsection{Conclusions}

In chapter 2, it appeared that either-or- or preserved $-r$ - is the regular reflex of ${ }^{*} r$ in Mycenaean. A scrutiny of the epigraphic evidence for the first millennium dialects (with the exception of Ionic-Attic dialects) has yielded the following results:

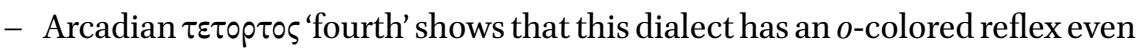
in non-labial environments, and that the anaptyctic vowel regularly devel-

106 Skelton (2017:113) suggests that the spellings $\pi \varepsilon \rho \tau$ ' and A an attempt to write a syllabic liquid", but this seems risky in view of the scanty evidence. She also asserts that the forms "could very well have come from Cretan", which would fit the foundation myth reported by Herodotus (1.173) "that the Lycian Sarpedon led a group of Cretans to settle in Lycia." (Skelton 2017: 110). However, as she equally admits, the difference between $\pi \varepsilon \rho \tau$ ' and Cretan $\pi \circ \rho \tau \iota$ "requires some explanation". 
ops before the liquid. As far as the vowel color is concerned, this conclusion

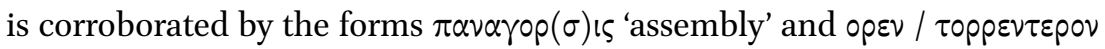
'male'.

- In Cyprian, the verbal form ka-te-wo-ro-ko-ne 'they beleaguered' and the personal name to-ro-su-ta-mo-se display a regular o-colored reflex, the latter in a non-labial environment. The vowel color is supported by the forms xop-

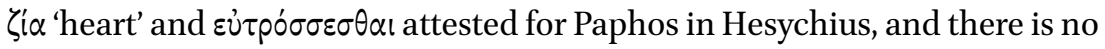
secure evidence for an $a$-colored outcome. However, the regular vowel slot remains uncertain in view of the orthographical ambiguity of the syllabary.

- The Aeolic dialects have regular $o$-coloring and develop the vowel after the liquid. This appears most clearly from Lesbian and Boeotian. The conclusions for Lesbian rely heavily on evidence from literary sources, but this is relatively clear-cut and is backed up by evidence from inscriptions. The

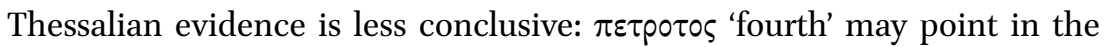
same direction, but numeral forms are generally difficult to evaluate because analogical remodeling may have played a role.

- Central Cretan did not undergo a liquid metathesis, as is widely believed, but developed the vowel before the liquid. The regular reflex in Cretan dialects is - $\alpha \rho$-, and probably -op- after a labial consonant. ${ }^{107}$ The situation on Thera (and in its colony Cyrene) seems to be similar, but the evidence is slight and consists mainly of personal names.

- The situation in most other West Greek dialects is similar to that in IonicAttic (general $a$-coloring), but the precise details may differ per dialect, and the evidence is often too scanty to allow for solid conclusions. In Elis ( $\beta p \alpha \tau \dot{\alpha}-$ $\nu \alpha \nu$ 'ladle', $\beta p \alpha \tau \alpha$ 'vel 'stirs' in Hesychius) and Syracuse (middle pf. है $\mu \beta p \alpha \tau \alpha l$ 'is fated', aor. हैं $\pi \rho \alpha \delta \varepsilon \varsigma$ 'farted') there is some evidence for - $\rho \alpha$ - as a regular reflex. The divergence between Central Cretan on the one hand, and the dialects of Elis and Syracuse on the other, shows that ${ }^{*} r$ had not yet vocalized in ProtoWest Greek. The situation in other West Greek dialects could benefit from a more detailed investigation.

- There is no clear evidence for the outcome of PGr. * ${ }^{*}$ in Pamphylian, nor any compelling evidence for liquid metathesis in this dialect.

More generally, the results of this chapter can be summarized as follows. First of all, not all Greek dialects developed a vowel after the liquid, nor was there a fluctuation between both positions. Rather, the evidence suggests that in each

107 In chapters 6 and 7 , I will argue that Epic Greek had a special reflex ${ }^{*} r>-\rho \alpha-$, but $-\rho \circ-$ after a labial consonant. The conditions for this change are the same as in Cretan, but the outcome is different. I therefore see no reason to assume a special relation between the Cretan development and that of Epic Greek. 
individual dialect, there was only one regular position where the anaptyctic vowel developed. It developed after the liquid in Proto-Aeolic and some West Greek dialects, but before the liquid in Central Cretan and Arcadian. Secondly, Aeolic, Arcadian and Cypriot have unconditioned $o$-colored reflexes, but Central Cretan probably shows a conditioned outcome (o $\rho$ after labial sounds, $\alpha \rho$ elsewhere). 